\title{
A Review on Durability Properties of Strain Hardening Fibre Reinforced Cementitious Composites (SHFRCC)
}

Shaikh Faiz Uddin Ahmed* and Hirozo Mihashi

Graduate School of Engineering, Tohoku University, Aoba 06, Aoba-Ku, Sendai 9808579, Japan.

\begin{abstract}
:
This paper reviews and presents various durability properties of strain hardening fibre reinforced cementitious composites (SHFRCC). Published research results show that, due to its tight crack width properties compared to ordinary concrete and ordinary fibre reinforced concrete, SHFRCC significantly resists the migration of aggressive substances in to the concrete and improves the durability of reinforced concrete (RC). It is also reported that, due to the strain hardening and multiple cracking behaviours, SHFRCC meets the tight crack width limits for durability of RC structures proposed by different design codes. Based on the reviewed durability properties it is argued that SHFRCC materials can be used in selected locations of RC structural members to improve their overall durability performances.
\end{abstract}

Key words: Durability, fibre reinforced cementitious composites, fibres.

*Corresponding author (Fax:+81-22-795-4772, email: shaikhfa@rocketmail.com)

\section{Introduction}

Numerous reinforced concrete (RC) structures are deteriorating worldwide. Many $\mathrm{RC}$ structures deteriorate long before their design service life and it is estimated that the average service life of RC structures can be as short as several decades [1]. Ordinary concretes are quasi-brittle with low tensile strain capacity resulting in the formation of cracks in the RC structures either under mechanical service loads or climatic loads or both. The cracks that form in such RC structures are wide enough for the deteriorating substances, such as chloride ions, to reach the steel reinforcement resulting in corrosion initiation. The durability of RC structures is also affected by other factors, such as freezing and thawing in cold weather, shrinkage cracking, etc. 
Over the last couple of decades, there has been a growing interest among researchers to develop strain hardening fibre reinforced cementitious composites (SHFRCC) containing randomly distributed short fibres of relatively low volume fractions. Engineered cementitious composites (ECC) are one of the most significant developments in the field of SHFRCC. ECC is ultra ductile cement based composites reinforced with short random fibres (metallic and/or nonmetallic) which exhibit strainhardening and multiple-cracking behaviors in uni-axial tension as well as in bending [2-5, $7-8,10-12]$. It is a strain hardening type of fibre reinforced cementitious composite that is microstructurally tailored based on micromechanics [3-5, 10-12]. ECC typically has tensile strain capacity of more than $3 \%$, with spacing between multiple cracks at saturation less than $3 \mathrm{~mm}$ and maximum crack width less than 100 micrometers. Microstructure optimization allows ECC to be made with fibre content less than $2 \%$ by volume. Ductile fibre reinforced cementitious composites (DFRCC) is another class of SHFRCC that exhibit multiple cracking behavior in bending $[6,8,9]$ as defined by the Japan Concrete Institute committee on DFRCC [13].

SHFRCC has higher fracture resistance capacity than that of ordinary concrete and regular fibre reinforced concrete. An important feature of SHFRCC composites exhibiting strain hardening and multiple cracking behaviour is the increase of postcracking strength beyond first crack strength accompanied by the development of closely spaced multiple cracks. SHFRCC containing mono fibres [2-5] and hybrid fibres have also been developed [6-9]. SHFRCC exhibits superior crack width and spacing control in the pseudo strain-hardening phase, as depicted in Fig. 1. A typical example of multiple cracking of SHFRCC in uni-axial tension is shown in Fig. 2. Superior tensile strain hardening response of ECC can be engineered by tailoring the composite ingredients with the aid of micromechanically based formulations [5, 7, 10-12].

This paper reviews and presents some of the most important durability properties of the SHFRCC materials, such as crack width control, permeability in cracked state, corrosion resistance, freeze-thaw resistance, performance in hot environments, shrinkage cracking resistance, and combined mechanical and environmental loads. 


\section{Crack width control and durability of SHFRCC}

The durability of RC structures can be enhanced by controlling the width of the crack. Load and environmentally-induced cracks are inherent in RC structures. The crack width in $\mathrm{RC}$ flexural members scales with the square root of concrete cover thickness [14]. Therefore, the width of exposed cracks increases as the cover thickness increases. Attempts to reduce the crack width by reducing the concrete cover thickness will lead to much worse corrosion, as it becomes easier for corrosive substances to penetrate and reach the reinforcement through the smaller cover of concrete material. Current design codes [15-18] limit the crack width in RC structures for corrosion protection. A summary is given in Table 1. The crack width limits for an aggressive environment are so low that they are generally difficult to achieve in practice using common reinforcing steel and conventional concrete due to the incompatible tensile deformation of concrete with steel in RC as shown in Fig. 3(a). For the case of reinforced SHFRCC numerous multiple cracks of small width are formed due to its strain hardening behaviour and compatible tensile deformation with steel (Fig. 3(b)). The cracks that form are small in width and will satisfy the crack width limit for durability imposed by the design codes. The addition of fibres in the concrete to reduce the crack width is a widely used method. The reduction of crack width in RC beams using the steel fibres is reported by Balazs and Kovacs [19].Lawler et al. [20] also reported the significant reduction of crack width due to the addition of micro and macro fibres in the concrete.

Control of crack width using SHFRCC has been demonstrated by several researchers. The earliest report of crack width measurement is by Maalej and Li [21], where polyethylene fibre reinforced ECC is used to replace the concrete that surrounds the main flexural reinforcement in a $\mathrm{RC}$ beam. It is shown that the maximum crack width in the beam under service load can be limited to values that are difficult to achieve using conventional steel reinforcement and commonly used concrete. In their study the average crack width under service load in the ECC layer at the bottom of the beam was found to be $0.10 \mathrm{~mm}$ (Fig. 4). Average crack width of about $0.060 \mathrm{~mm}$ in ECC containing Polyvinyl Alcohol (PVA) fibres in uniaxial tension are also reported by Li et al.[4]. Other studies that included crack width measurements were reported by Weimann and Li [22] and Wang and Li [23]. In all of these studies PVA fibres were used and the average crack 
width of about $0.060 \mathrm{~mm}$ is achieved. The above results clearly show that the cracks that form in the SHFRCC under service load are small enough to resist the penetration of aggressive substances and the durability of RC structures can be enhanced greatly using this material.

\section{Permeability characteristics of cracked SHFRCC}

High permeability, due to porosity or cracking, facilitates the ingress of water, chlorides, and other corrosive agents. If such agents reach reinforcing bars within the structure, bar corrosion can occur thus compromising the ability of the structure to withstand loads. Reinforcing fibres significantly reduces the water permeability through the modification of crack topography. The study by Tsukamoto and Worner [24] indicated that the fibres in the concrete reduces the flow rate at a given crack width and increases the critical crack width below which no further flow occurs. Improved resistance against permeability of cracked steel fibre reinforced concrete and mortar over cracked ordinary concrete/mortar is also reported by Lawler et al. [25] and Rapoport et al. [26].

Most of the design codes recommend limits for allowable maximum crack width in the $\mathrm{RC}$ as a function of exposure conditions, the limits for aggressive environments are unrealistic when considering costs and available resources of conventional practice of ordinary RC. Although cracking in concrete structures cannot be completely avoided, more effective means to control cracking in the RC members must be attempted in order to prevent excessive permeability. Since the permeability significantly influences the deterioration of concrete, evaluation of permeability in cracked SHFRCC is a key factor to describe the durability performance of given materials. The tight crack widths of SHFRCC under load of below 60-100 micrometers points to its superior resistance against permeation.

Lepech and Li [27] studied the water permeability of cracked SHFRCC and reinforced mortar specimens. When subjected to identical tensile deformation, the SHFRCC and the reinforced mortar specimens exhibited very different cracking patterns and widths. The cracked SHFRCC exhibits nearly the same permeability as sound concrete, even when strained in tension to several percent (Fig. 5). Note that both the SHFRCC and reinforced mortar specimens were stretched in tension to identical 
deformation ( $1.5 \%$ tensile strain) resulting in a variety of crack widths and number of cracks among various specimens. The SHFRCC specimens showed closely spaced microcracks with crack widths of approximately $0.060 \mathrm{~mm}$, while reinforced mortar with varying reinforcement ratios showed crack widths ranged between $0.150 \mathrm{~mm}$ and over $2.5 \mathrm{~mm}$. The permeability of these cracked materials was then determined under hydraulic head. As can be seen in Fig. 6, there is a dramatic rise in permeability with increasing crack width. Further, when normalized by number of cracks within the specimen, the comparable permeability of cracked SHFRCC with sound material becomes more apparent.

In another study, Martinola et al. [28] evaluated the water permeability of cracked and uncracked SHFRCC by water absorption test. In their study, the amount of water taken up by capillary suction was determined on cubes cut out from the middle section of the beams which were subjected to four point bending test. Maximum crack width in the cracked SHFRCC specimens was found to be about $0.10 \mathrm{~mm}$ and cracked SHFRCC exhibited very low water absorption coefficient.

No systematic study of chloride permeability of cracked SHFRCC has been performed to date. However, comparative tests on steel reinforced concrete or mortar beams $(\mathrm{R} / \mathrm{C}$ or $\mathrm{R} /$ mortar) and steel reinforced SHFRCC (R/SHFRCC) beams were performed by Maalej et al. [29] and Miyazato and Hiraishi [30]. Maalej et al. [29], measured the chloride contents in concrete and SHFRCC by collecting concrete powder at the level of reinforcement in cracked concrete and SHFRCC beams. The bottom half of all beams in their study were submerged in water containing $3 \% \mathrm{NaCl}$ (by wt.) and were subjected to cyclic wetting and drying for about 83 days. The results showed that the chloride content in the SHFRCC beams was much lower (about 4 times lower) than that of the RC beam. Miyazato and Hiraishi [30] also reported experimental results on the measurement of chloride penetration depth in small scale cracked $\mathrm{R} /$ mortar and $\mathrm{R} / \mathrm{SHFRCC}$ beams. The beams were subjected to accelerated chloride exposure conditions (with $3.1 \% \mathrm{NaCl}$ by wt.), with alternating wet and dry cycles for 28 days. Results showed that, in the case of the $\mathrm{R} /$ mortar beams, the chloride penetration depth was approximately $80-100 \mathrm{~mm}$ depending on the w/c ratio of the mix (Fig. 7). In the case 
of the R/SHFRCC beams, the chloride penetration occurred at multiple locations corresponding to where the multiple cracks were formed during the pre-load (Fig. 7). However, the penetration depth was much shallower, between 0 and $20 \mathrm{~mm}$ in R/SHFRCC beams (Fig. 8). Similar results were also reported in the case of carbonation penetration into the cracked R/SHFRCC beams (Fig. 8) [30].

In another study, Ogawa et al. [31] studied the chloride ion penetration resistance of beams made with ordinary concrete and SHFRCC. Both specimens were cured under water for 38 days and were soaked in artificial sea water containing 1.8\% chloride ion concentration for 30 and 60 days. Test results showed that in the case of ordinary concrete specimens the chloride ion concentration was about $0.04 \%$ after 60 days of soaking, whereas in the case of SHFRCC specimens the chloride ion concentration was only $0.005 \%$, about 10 times lower than that of ordinary concrete. The above results on the permeability of SHFRCC show that it has very low water and chloride permeability.

In addition to the low water and chloride permeability of cracked SHFRCC described above, the small width of these multiple microcracks has the potential to promote self-healing. For example, Edvardsen [32] showed that the dominant factor for promoting self-healing in concrete is a small crack width. Preliminary observations on self-healing tendency of the cracked SHFRCC specimens subjected to cyclic wetting and drying regimes are reported by Yang et al. [33] (Fig. 9). The expected self-healing ability of cracked SHFRCC will further enhance the durability of RC structures built with such materials. Systemic study of this phenomenon in SHFRCC is required to confirm this trend.

In reality, however, RC structures under mechanical loads are often subjected to the environmental influences. Since the crack width may be closed after unloading, permeability test needs to be done under sustained loads particularly under strain hardening stage in SHFRCC. SHFRCC is often made with cement rich mix-proportions and shrinkage cracking easily occurs at the early ages. Shrinkage cracking may have some different geometry from that under mechanical loading. Although in the restrained shrinkage tests the crack widths of this material was found to be small enough to resist the permeation of aggressive substances, however, permeability of damaged SHFRCC due to shrinkage cracking should also be studied. 


\section{Corrosion resistance of SHFRCC}

Corrosion of reinforcing steels is considered as the main cause for the deterioration of RC structures world wide. The use of fibres in reinforced concrete has exhibited improved corrosion resistance in several studies [34-38]. In a study by Shui and Stroeven [34], the corrosion rate of steel bar in carbon fibre reinforced concrete reduced with increase in fibre contents. However, after a certain fibre content the corrosion rate increased with increase in fibre contents. Improved corrosion resistant of carbon fibre reinforced concrete is also reported by Hou and Chung [35]. Sanjuan et al. [36] reported improved corrosion resistance of polypropylene fibre reinforced mortars over ordinary mortars. Other studies have indicated significant improvement of corrosion resistance of polypropylene fibre reinforced concrete over ordinary concrete [37-38].

Due to the strain hardening behaviour and fine multiple cracks the SHFRCC exhibits better corrosion resistance than that of ordinary concrete. In 1995, Maalej and Li [21] proposed a more promising approach to address the problem of corrosion durability in RC structures using SHFRCC. Their study [21] introduced a concept of functionallygraded cementitious composite (FGC) beams, in which the bottom layer of the beam including the part surrounding the main flexural reinforcement was cast with the SHFRCC. It was suggested that the SHFRCC material in the FGC beams could provide two levels of protection. First, it could prevent the migration of aggressive substances into the concrete, therefore, preventing reinforcement corrosion. Second, in the extreme case when corrosion initiates, accelerated corrosion due to longitudinal cracks would be reduced if not eliminated and spalling and delamination problems common to many of today's RC structures would be prevented. This was expected due to the high strain capacity and fracture resistance of the SHFRCC material. Later, Maalej et al. [29] evaluated the effectiveness of the proposed concept through experimental study in retarding the corrosion of reinforcing steel and to reduce the tendency of the cover to delaminate in the FGC beams containing SHFRCC layer. The FGC beams exhibited lower level of steel loss and longer time to achieve the same level of steel loss than RC beam (Fig. 10). The FGC beams also exhibited no corrosion induced cracks/damage as indicated by the lowest tendency of the cover concrete to delaminate measured by an embedded fibre optic strain sensor (FOSS) gauge (Fig. 11). In a study reported by 
Miyazato and Hiraishi [30] negligible corrosion of steel in cracked R/SHFRCC beam is observed compared to high macro and micro-cell corrosion at the location of cracks in a R/mortar beam (Fig. 12).

While SHFRCC showed superior protection of steel against corrosion in RC, only one study evaluated its potential against corrosion induced cracking and particularly against spalling/delamination of cover concrete in the RC beams. In the study by Maalej et al. [29] resistance of SHFRCC against spalling/delamination of cover concrete was evaluated only under $10 \%$ calculated steel loss (Note that the actual steel loss in the beam was much less than the calculated value). Therefore, the resistance of SHFRCC against spalling/delamination of cover concrete under heavily corroded reinforcing bars in RC beams need to be evaluated to confirm its potential.

\section{Resistance of SHFRCC against freeze and thaw durability}

One of the most damaging environmental conditions to reinforced concrete is cyclic freezing and thawing in cold regions. Damage induced by frost action into concrete coarsens the pore structure and as a consequence rate of carbonation and chloride penetration accelerate considerably [39]. The volume expansion of pore water in the concrete during freezing also cause the $\mathrm{RC}$ structures to crack and the subsequent use of deicing salts to thaw the ice cause the reinforcing steels to corrode rapidly. The effectiveness of SHFRCC for improved durability against freezing and thawing has been evaluated by limited number of researchers. Lepech and Li [40] evaluated the durability of SHFRCC and ordinary concrete upto 300 freeze-thaw cycles. In their study, SHFRCC and normal concrete prism specimens (both without air entrainment) were subjected to cyclic freeze-thaw testing over 14 weeks. Results showed that after 5 weeks (110 cycles), the concrete specimens had deteriorated severely. However, all SHFRCC specimens survived 300 cycles with no degradation of dynamic modulus. This performance resulted in a durability factor of 10 for concrete compared to 100 for SHFRCC, as computed according to ASTM C666 [40]. It should be noted that in that study this high durability was achieved without deliberate air entrainment into the SHFRCC. In addition uniaxial tension tests were also performed on wet cured and freeze-thaw exposed SHFRCC specimens, and no significant drop in strain capacity was observed even after 300 cycles. 
Superior freeze-thaw durability of SHFRCC specimens over ordinary concrete was also reported by Ogawa et al. [31]. In their study both SHFRCC and ordinary concrete specimens were also subjected to 300 freeze and thaw cycles. After every hundred cycles dynamic modulus of elasticity of SHFRCC specimens was measured and negligible reduction in the dynamic modulus of elasticity in SHFRCC was observed even after 300 cycles. Four point bending tests were also performed on wet cured and freeze thaw exposed SHFRCC specimens and no significant drop in flexural strength capacity was reported even after 300 cycles.

\section{Behaviour of SHFRCC at elevated temperatures}

In contrast to freeze thaw tests discussed earlier, which are designed to simulate temperature changes in cold weather, hot water immersion tests on SHFRCC specimens were also conducted to evaluate their long term performance in hot and humid environments. To examine the effects of environmental exposure, hot water immersion was performed by Li et al. [41] on individual PVA fibres, single fibres embedded in SHFRCC matrix, and composite SHFRCC material specimens. After 26 weeks in hot water immersion $\left(60^{\circ} \mathrm{C}\right)$, little change was seen in fibre properties such as fibre strength, fibre elastic modulus, and elongation. Interfacial properties, however, experienced significant changes, particularly between 13 and 26 weeks of immersion. During this time, the chemical bonding between PVA fibre and matrix strengthened, while the apparent strength of the fibre dropped (Fig. 13). This change in interfacial properties resulted in a drop of ultimate strain capacity of the PVA fibre reinforced SHFRCC specimens. The strain capacity of the SHFRCC dropped from $4.5 \%$ at early age to $2.75 \%$ after 26 weeks of hot water immersion (Fig. 14). While accelerated hot weather testing does result in lower strain capacity of SHFRCC, the $2.75 \%$ strain capacity, over 250 times that of normal concrete, is still acceptable for nearly any repair/retrofit application [41]. In a separate study, Horikoshi et al. [42] soaked PVA and alkali resistant (AR) glass fibres into hot $\left(80^{\circ} \mathrm{C}\right)$ and high alkaline water for two weeks. No reduction in tensile strength of PVA fibres were observed after two weeks, whereas significant reduction in tensile strength of AR glass fibres were reported in their study. PVA and AR glass fibres reinforced mortar specimens were also soaked in $60^{\circ} \mathrm{C}$ hot water for 28 days in their 
study. PVA fibre reinforced mortar specimens did not show any significant reduction in modulus of rupture value whereas AR glass fibre reinforced mortar specimens exhibited a reduction of about $30 \%$ of its initial modulus of rupture value (Fig. 15).

\section{Resistance of SHFRCC against shrinkage cracking}

Shrinkage is one of the major origins of crack formation in RC structures. Due to the strain hardening and multiple cracking behaviour the SHFRCC behaves differently under restrained shrinkage compared to ordinary concrete. The restrained shrinkage behaviour of SHFRCC was examined by several researchers through ring tests. Weimann and $\mathrm{Li}$ [22] evaluated the restrained shrinkage of SHFRCC by ring test. Their results showed that due to the high cement content higher free shrinkage deformation was observed in SHFRCC compared to normal concrete. However, restrained shrinkage tests show that although hygral deformation of SHFRCC is higher, the crack widths in SHFRCC remain below $0.050 \mathrm{~mm}$ (cured at constant $50 \%$ relative humidity for 100 days), compared to concrete crack widths of approximately $1 \mathrm{~mm}$ (Fig. 16). This is achieved through the microcracking of SHFRCC, allowing the shrinkage deformation to be distributed over a large number of small cracks, while all shrinkage deformation in concrete localizes at a single crack.

Wittmann et al. [43] also evaluated the restrained shrinkage behaviour of SHFRCC and ordinary mortar using ring tests. Results showed that, in the case of ordinary mortar a single crack was formed with a maximum crack width of $8.5 \mathrm{~mm}$. In contrast about 10 cracks were observed in SHFRCC ring specimens with maximum crack width in the range of $0.05 \mathrm{~mm}$ to $0.11 \mathrm{~mm}$ (Fig. 17) (depending on fibre volume fractions). In an another study, Martinola and Bauml [44] evaluated the restrained shrinkage induced cracking of SHFRCC and ordinary mortar in reinforced beam test. In their study, $1 \mathrm{~m}$ long $\mathrm{RC}$ beams of $150 \times 150 \mathrm{~mm}$ in cross-section were cast using SHFRCC and ordinary mortar. In the case of RC beam containing ordinary mortar eight vertical cracks were formed with a maximum crack width of $0.16 \mathrm{~mm}$. In contrast about 16 cracks were observed in RC beams containing SHFRCC with a maximum crack width of $0.05 \mathrm{~mm}$. 
Recently, Ahmed et al. [45] also evaluated the restrained shrinkage cracking of light weight hybrid fibre SHFRCC against shrinkage induced cracking. Ring specimens were used in their study. Two types of light weight hybrid fibre SHFRCC are considered. Results showed the multiple cracks, as many as 49 , in light weight hybrid fibre SHFRCC specimens compared to a localized single crack in one type of premix mortar specimen (Premix mortar-II) and about six cracks in another type of premix mortar specimen (Premix mortar-I) (Fig. 18). At the end of the shrinkage tests, the final crack width in the premix mortar-II specimen was about $1.4 \mathrm{~mm}$ (Fig. 19). In case of Premix mortar-I, the width of almost all cracks was more than $0.25 \mathrm{~mm}$. However, the scenario was quite different in the light weight hybrid fibre SHFRCC, where the width of almost all cracks was less than $0.15 \mathrm{~mm}$.

\section{Behaviour under combined mechanical and environmental loads}

Another important factor for the durability study of $\mathrm{RC}$ is the similarity of the test conditions to the real situation of concrete structures. RC structures in the field often experience combined mechanical and environmental loading during their service life. The durability properties of SHFRCC were not only evaluated in the laboratory but its durability was also evaluated in the filed under combined loads. Lepech and Li [40] reported a field durability study of SHFRCC where one section of a deteriorated bridge deck was repaired with the SHFRCC while the remaining portion was repaired with a commercial concrete patching material. This repair scenario allowed for a unique SHFRCC/concrete comparison subjected to identical environmental and traffic loads. The concrete repair material used was a pre-packaged mixture of Portland cement and plaster of Paris [40]. After 4 months of winter exposure in Michigan, USA, a number of small microcracks, each roughly $0.050 \mathrm{~mm}$ wide, were formed within the SHFRCC patch repair, while the crack observed in concrete patch repair shortly after casting was widened to $2 \mathrm{~mm}$ and was surrounded by deteriorated and spalling concrete. After 30 months, the maximum crack width in SHFRCC was still $0.050 \mathrm{~mm}$, while sections of the concrete patch were severely deteriorated. The development of crack width over time in both SHFRCC and concrete patching material is shown in Fig. 20. 


\section{Conclusions}

Available test data and field results indicate that SHFRCC exhibits excellent durability properties. The strain hardening and multiple cracking behaviour, together with very small crack width properties, provide very low water and chloride permeability, which retards the onset of corrosion of reinforcing steel in $\mathrm{RC}$ and reduces the potential corrosion rate. The higher strain capacity and fracture resistance of this material over ordinary concrete also enable it to reduce the corrosion induced damage. The same properties lead to superior performance with respect to other durability concerns, such as restrained shrinkage induced cracking, cracking and damage due to freeze and thaw, etc. However, additional research is needed on the durability performance of SHFRCC, particularly with respect to its performance under combined mechanical and environmental loading.

\section{Acknowledgement}

The first author would like to acknowledge the financial assistance in the form of postdoctoral fellowship from the Japan Society for Promotion of Science (JSPS).

\section{References:}

[1]Proceedings of International Workshop on Durability of Reinforced Concrete under Combined Mechanical and Climatic Loads, Qingdao Technological University, Qingdao, China. (Zhao, T.J., Wittmann, F.H. and Ueda, T. editors). Aedificatio publishers, Germany, 2005, pp. 300.

[2]Li, V.C. 2003 On Engineered cementitious composites: A review of the material and its applications. Journal of Advanced Concrete Technology, 1(3): 215-230.

[3]Kanda, T. and Li, V.C. 2006 Practical design criteria for saturated pseudo strain hardening behaviour in ECC. Journal of Advanced Concrete Technology, 4(1): 59-72.

[4]Li, V.C., Wang, S. and Wu, C. (2001). Tensile strain-hardening behaviour of Polyvinyl Alcohol Engineered Cementitious Composites (PVA-ECC). ACI Materials Journal, Nov.-Dec. 2001, pp. 483-492. 
[ 5]Kanda, T. and Li, V.C. (1999). A new micromechanics design theory for pseudo strain-hardening cementitious composite. ASCE Journal of Engineering Mechanics, 124(4), pp. 373-381.

[ 6]Ahmed, S.F.U. Maalej, M. and Paramasivam, P. 2003. Strain-hardening Behaviour of Hybrid Fibre Reinforced Cement Composites. Journal of Ferrocement 33 (3): $172-$ 182.

[ 7] Ahmed, S.F.U. Maalej, M. and Paramasivam, P. 2005. Analytical Model for Tensile Strain Hardening and Multiple Cracking Behaviour of Hybrid Fibre Engineered Cementitious Composites. ASCE, Journal of materials in civil engineering, (Tentatively accepted).

[ 8]Kawamata, A., Mihashi, H. and Fukuyama, H. 2002. Material design of hybrid fibre reinforced cementitious composites. Journal of Advanced Concrete Technology, 1(3): 283-290.

[ 9]Ahmed, S.F.U. Maalej, M. and Paramasivam, P. 2006. Flexural responses of hybrid steel-polyethylene fibre reinforced cement composites containing high volume fly ash. Journal of construction and building materials (In Press).

[10] Li, V.C. and Wu, H.C. (1992). "Conditions for pseudo strain-hardening in fibre reinforced brittle matrix composites", Applied Mech Review, 45(8), 390-398.

[11] Li, V.C. (1992). "Post-crack scaling relations for fibre reinforced cementitious composites", J. of Materials in Civil Eng, ASCE, 1.4(1), 41-57.

[12] Li, V.C., and Leung, C.K., (1992) "Steady state and multiple cracking of short random fibre composites", Journal. of Engineering Mechanics, ASCE, 118(18), 22472264.

[13] JCI-DFRCC Committee, Technical report on the terminology, Journal of Advanced Concrete Technology, Vol.1, No.3, 2003, pp. 335-340.

[14] Gergely, P. and Lutz, L.A., (1973) "Maximum crack width in reinforced concrete flexural members" In cases, mechanism and control of cracking in concrete, ACI special publication, $\mathrm{SP}-20$, pp. 87-117.

[15] ACI Committee 222, (1991) "Corrosion of metals in concrete," ACI Manual of Concrete Practice Part 1- 1991: Materials and General Properties of Concrete, American Concrete Institute, Detroit, USA. 
[16] ACI Committee 224, (1991) "Control of Cracking in Concrete Structures," ACI Manual of Concrete Practice Part 3-1991: Use of Concrete in Buildings-Design, Specifications, and Related Topics, American Concrete Institute, Detroit, USA.

[ 17] BS 8110: Part 2, (1985) "Structural use of concrete: Part 2:1985 Code of practice for special circumstances", British Standard Institution, London, UK, pp.3/1.

[ 18] CEB-FIP model code 90, (1990) "CEB-FIP Model Code for Concrete Structures", Comité Euro-International du Béton (CEB), Lausanne, Switzerland.

[19] Balazs, G.L. and Kovacs, I. (2004) Effect of steel fibers on the cracking behaviour of RC members. In the proc. $6^{\text {th }}$ RILEM symposium on FRC-BEFIB 2004, Italy, pp 1007-1016.

[20] Lawler, JS, Zampini, D. and Shah, SP (2004) Microfiber and macrofiber hybrid fiber-reinforced concrete, ASCE, Journal of materials in civil engineering, Vol. 17 (5), pp. 595-604

[21] Maalej, M. and Li, V.C. (1995) Introduction of strain-hardening engineered cementitious composites in design of reinforced concrete flexural members for improved durability, ACI Structural Journal 92(2), 167-176.

[22] Weimann, M.B. and Li, V.C. (2003). Hygral Behaviour of Engineered Cementitious Composites (ECC), International Journal for Restoration of Buildings and Monuments Vol. 9, No 5, 513-534 (2003)

[23] Wang, S. and Li, V.C. (2005). Polyvinyl Alcohol Fibre reinforced engineered cementitious composites: material design and performances. Proceedings of Int'l workshop on HPFRCC in structural applications, Honolulu, Hawaii, USA, May 2326, 2005.

[24] Tsukamoto, M. and Worner, J.D., (1990) "Tightness of Fiber Concrete," Darmstadt Concrete, Annual Journal on Concrete and Concrete Structures, V. 5, pp. 215-225.

[25] Lawler, JS, Zampini, D. and Shah, SP (2002) Permeability of cracked hybrid fiber-reinforced mortar under load, ACI Materials Journal, 99(4), pp. 379-385.

[26] Rapoport, J., Aldea, C.M., Shah, SP, Ankenman, B. and Karr, A. (2002) Permeability of cracked steel fiber reinforced concrete, ASCE, Journal of materials in civil engineering, Vol. 14 (4), pp. 355-358 
[27] Lepech, M. and Li, V.C. (2005). Water permeability of cracked cementitious composites, Proceedings of ICF, Torino, March, 2005.

[28] Martinola, G., bauml, M.F. and Wittmann, F.H., Modified ECC applied as an effective chloride barrier, Proceedings of the JCI International Workshop on Ductile Fibre Reinforced Cementitious Composites (DFRCC) - Application and Evaluation (DRFCC-2002), Takayama, Japan, Oct. 2002, pp.171-180.

[29] Maalej, M., Ahmed, S.F.U. and Paramasivam, P. (2002) Corrosion durability and structural response of functionally-graded concrete beams, Journal of Advanced Concrete Technology, 1(3): 307-316.

[30] Miyazato, S. and Hiraishi, Y., Transport properties and steel corrosion in ductile fibre reinforced cement composites, Proceedings of ICF, Torino, March, 2005

[31] Ogawa, A., Hitomi, Y. and Hoshiro H. (2005). PVA-fibre reinforced high performance cement board, Proceedings of Int'l workshop on HPFRCC in structural applications, Honolulu, Hawaii, USA, May 23-26, 2005.

[32] Edvardsen, C. (1999). Water permeability and autogenous healing of cracks in concrete, ACI Materials Journal, 4, pp. 448-454.

[33] Yang, Y., Lepech M. and Li. V.C. (2005) Self haeling of engineered cementitious composites under cyclic wetting and drying, In the proc. Int. workshop on durability of reinforced concrete under combined mechanical and climatic loads, China, 2005. pp. 231-242.

[34] Shui, Z. and Stroeven, P. (2000) Influence of carbon fibers on corrosion risks of steel bars in concrete. In the proc. $5^{\text {th }}$ RILEM symposium on FRC-BEFIB 2000, France, pp 665-670.

[35] Hou, J. and Chung, DDL (2000) Effect of admixtures in concrete on the corrosion resistance of steel reinforced concrete. Corrosion Science. Vol. 42, pp. 1489-1507.

[36] Sanjuan, MA, Andrade, C. and Bentur, A. (1998) Effect of polypropylene fiber reinforced mortars on steel reinforcement corrosion induced by carbonation. Materials and Structures, Vol. 31, pp. 343-349.

[37] Al-Tayyib, AH and Al-Zaharani, MM (1990) Corrosion of steel reinforcement in polypropylene fiber reinforced concrete structures, ACI Materials Journal, Vol. 87, No. 2, pp. 108-113. 
[38] Wheat, H.G. (2002) Using polymers to minimize corrosion of steel in concrete. Cement and concrete composites, Vol. 24, pp. 119-126.

[39] Wittmann, F.H., Zhang, P. and Zhao, T. (2006) Influence of combined environmental loads on durability of reinforced concrete structures, International Journal for Restoration of Buildings and Monuments Vol. 12, No 4, 349-361.

[40] Lepech, M. and Li V.C. (2005). Durability and long term performance of Engineered Cementitious Composites, Proceedings of Int'l workshop on HPFRCC in structural applications, Honolulu, Hawaii, USA, May 23-26, 2005.

[41] Li, V.C., Horikoshi, T, Ogawa, A, Torigoe, S and Saito, T (2004). Micromechanics-based durability study of Polyvinyl Alcohol-Engineered Cementitious Composite. ACI Materials Journal, May-June 2004, pp. 242-248.

[42] Horikoshi, T., Ogawa, A., Saito, T. and Hoshiro, H., (2005) Properties of PVA fibre as reinforcing materials for cementitious composites, Proceedings of Int'l workshop on HPFRCC in structural applications, Honolulu, Hawaii, USA, May 23$26,2005$.

[43] Wittmann, F., Furtwangler, K. and Mao, X., (2005) Optimising material properties by means of the instrumented ring test, Proceedings of Int'l workshop on HPFRCC in structural applications, Honolulu, Hawaii, USA, May 23-26, 2005.

[44] Martinola, G. and Bauml, M.F. (2002) Optimizing ECC in order to prevent shrinkage cracking, Proceedings of the JCI International Workshop on Ductile Fibre Reinforced Cementitious Composites (DFRCC) - Application and Evaluation (DRFCC-2002), Takayama, Japan, Oct. 2002, pp.143-152.

[45] S.F.U. Ahmed, H. Mihashi and S. Suzuki, Experimental study on restrained shrinkage-induced cracking of mortars with different toughness, To appear in the proceedings of fifth international conference on concrete under severe conditions: CONSEC07, Environment and loading, Tours, France, 2007.

[46] Mihashi, H., Nishiwaki, T. and Leite, JPdeB, Effectiveness of crack control on durability of HPFRCC, Proceedings of the HPFRCC-4, USA, 2003.

[47] Fischer, G. and Li, V.C. (2004) Effect of fibre reinforcement on the response of structural members, In the proc. of fracture mechanics of concrete structures, Li et al. (eds.), pp. 831-838. 
Table 1. Examples of limitation of design crack width shown in codes and standards.

\begin{tabular}{|c|c|c|c|}
\hline Country & Code/Standard & \multicolumn{2}{|c|}{ Limitation of crack width (mm) } \\
\hline Japan & JSCE Standard [46] & $\begin{array}{l}0.005 c \\
0.004 c\end{array}$ & $\begin{array}{l}\text { for steel bars } \\
\text { for prestressing bars } \\
(\mathrm{c}=\text { concrete cover })\end{array}$ \\
\hline U.S.A. & ACI Committee 222 [15] & $\begin{array}{l}0.33 \\
0.41\end{array}$ & $\begin{array}{l}\text { for exterior members } \\
\text { for interior members }\end{array}$ \\
\hline U.S.A. & ACI Committee 224 [16] & $\begin{array}{l}0.41 \\
0.30 \\
0.18 \\
0.25 \\
0.10\end{array}$ & $\begin{array}{l}\text { Dry air or protective membrane } \\
\text { Humid, moist air, soil } \\
\text { Deicing chemicals } \\
\text { Seawater, wetting and drying } \\
\text { Water retaining structures }\end{array}$ \\
\hline New Zealand & $\begin{array}{l}\text { New Zealand Standard } \\
{[46]}\end{array}$ & $\begin{array}{l}0.3 \\
0.2\end{array}$ & $\begin{array}{l}\text { for steel bars } \\
\text { for prestressing bars }\end{array}$ \\
\hline EU & $\begin{array}{l}\text { CEB-FIP model code } 90 \\
{[18]}\end{array}$ & 0.1 & for steel bars \\
\hline Norway & $\begin{array}{l}\text { Det Norske Veritas (1991) } \\
{[46]}\end{array}$ & 0.4 & except splashed part \\
\hline UK & BS 8110:Part 2 [17] & 0.3 & for steel bars \\
\hline
\end{tabular}

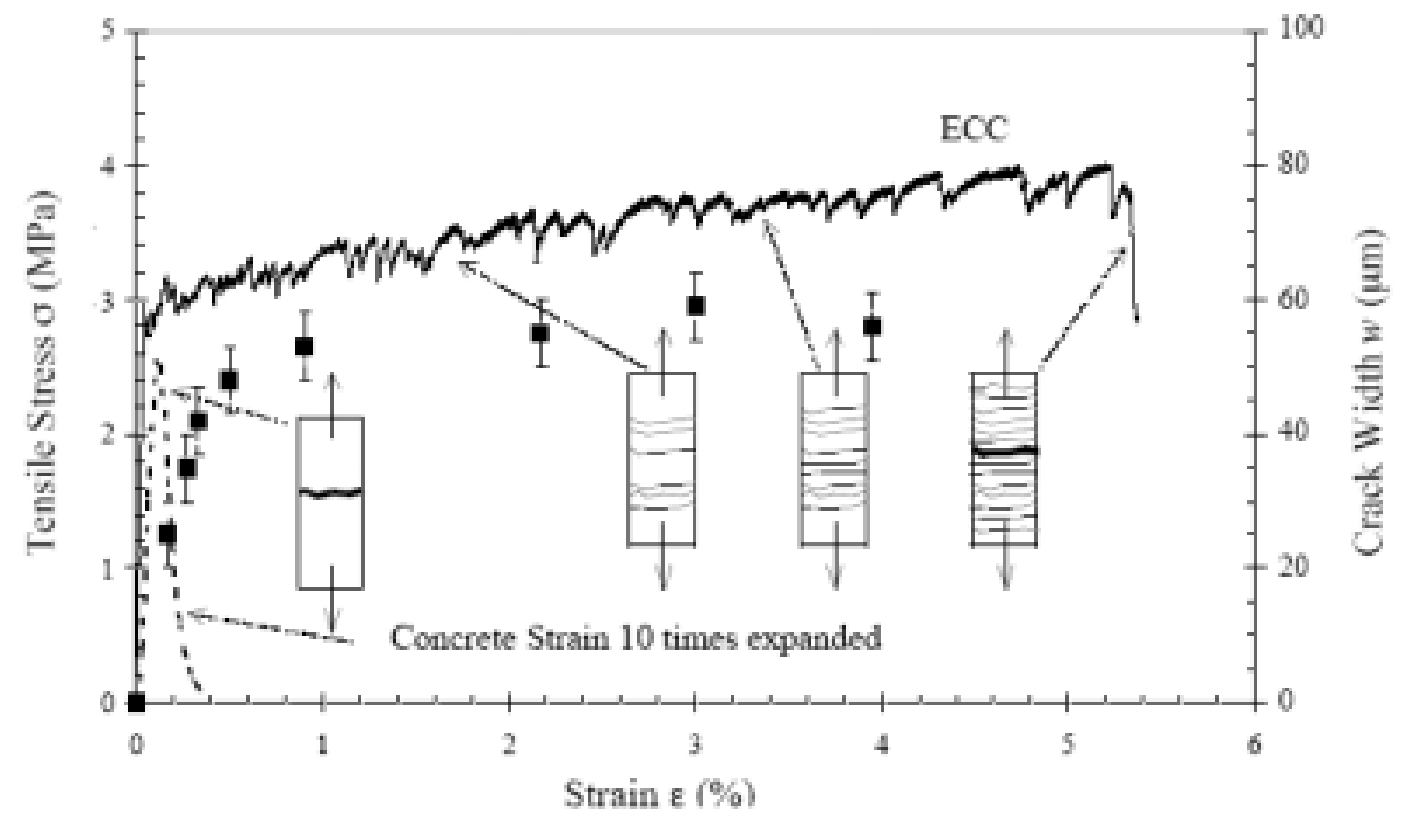

Fig. 1: Uni-axial tensile stress-strain response of SHFRCC showing finer, closely spaced cracks in SHFRCC [22]. 


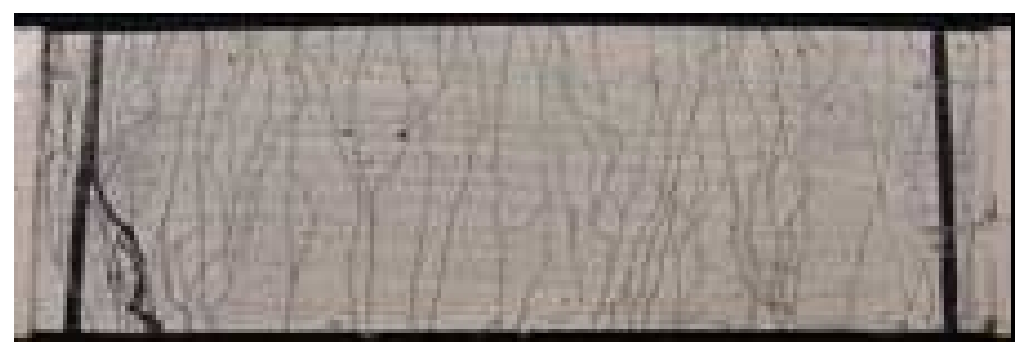

Fig.2 Typical example of multiple cracking of SHFRCC in tension [7].
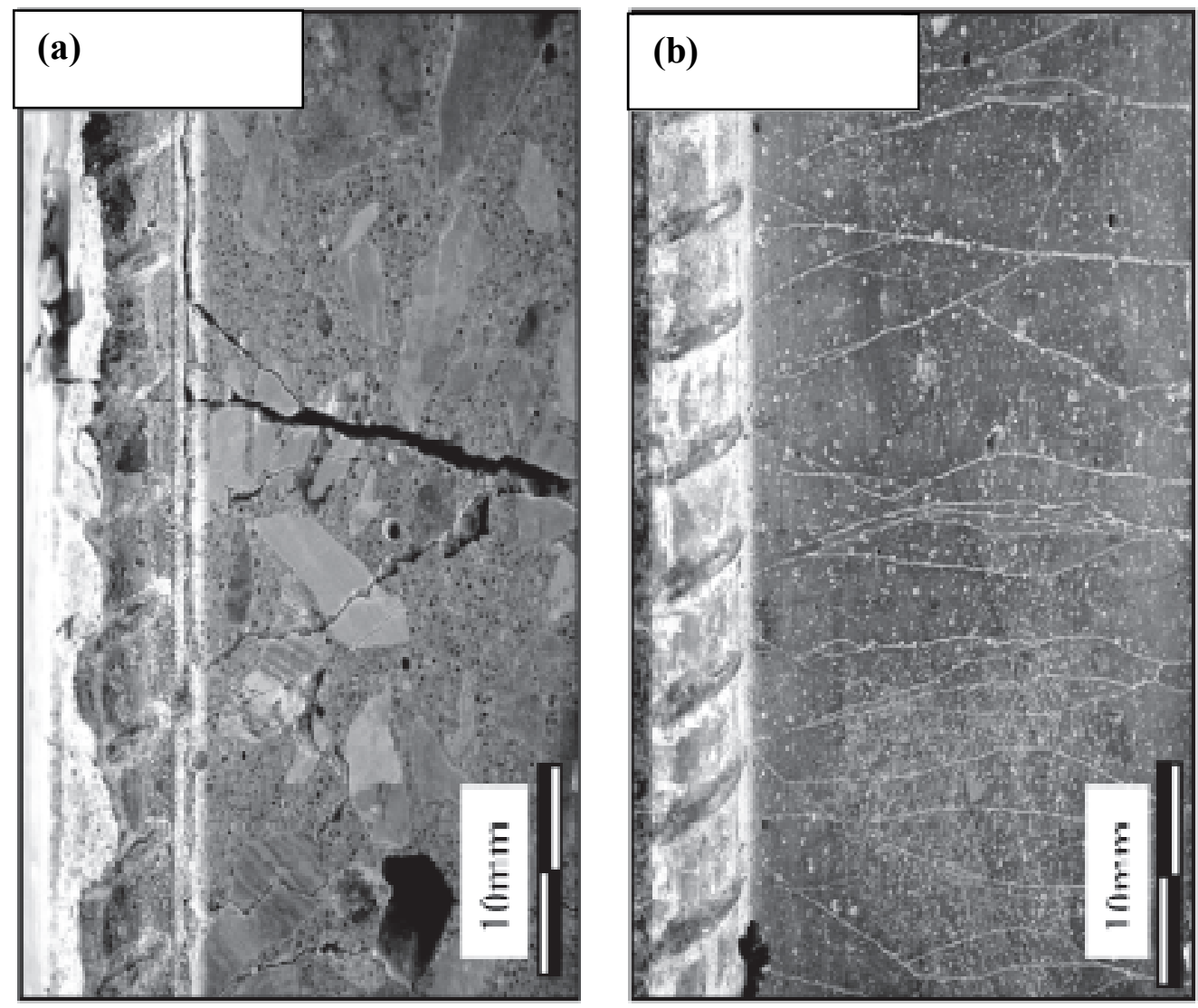

Fig. 3: Incompatible tensile deformation in $\mathrm{R} / \mathrm{C}$ (a) vs. compatible tensile deformation in $\mathrm{R} / \mathrm{SHFRCC}$ (b), through ductile, multiple cracking tensile response of SHFRCC [47]. 


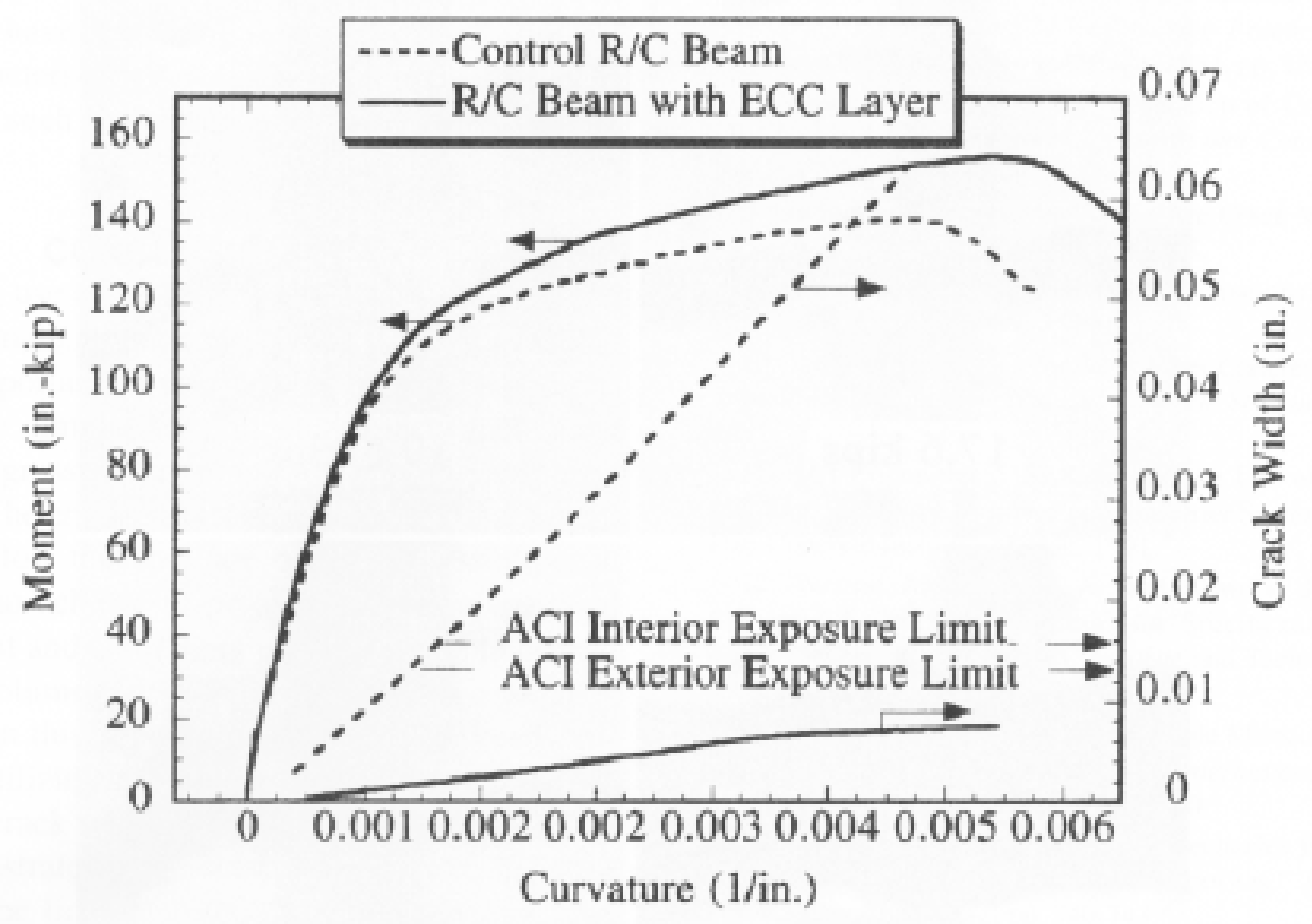

Fig. 4 Crack width of RC beam and RC beam with SHFRCC layer under flexural loading [21].

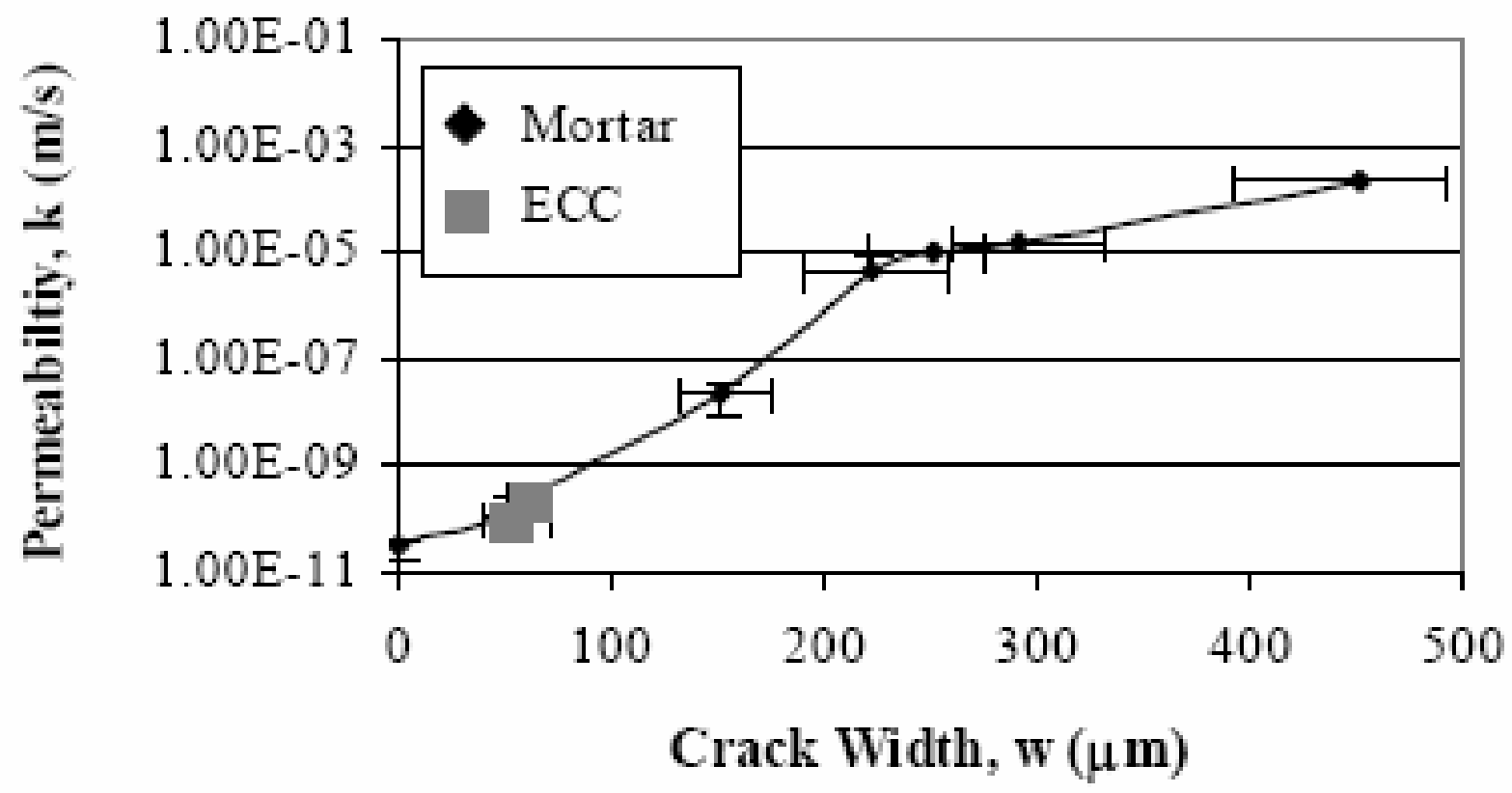

Fig. 5 Water permeability as function of crack width of cement-based composite materials [27]. 


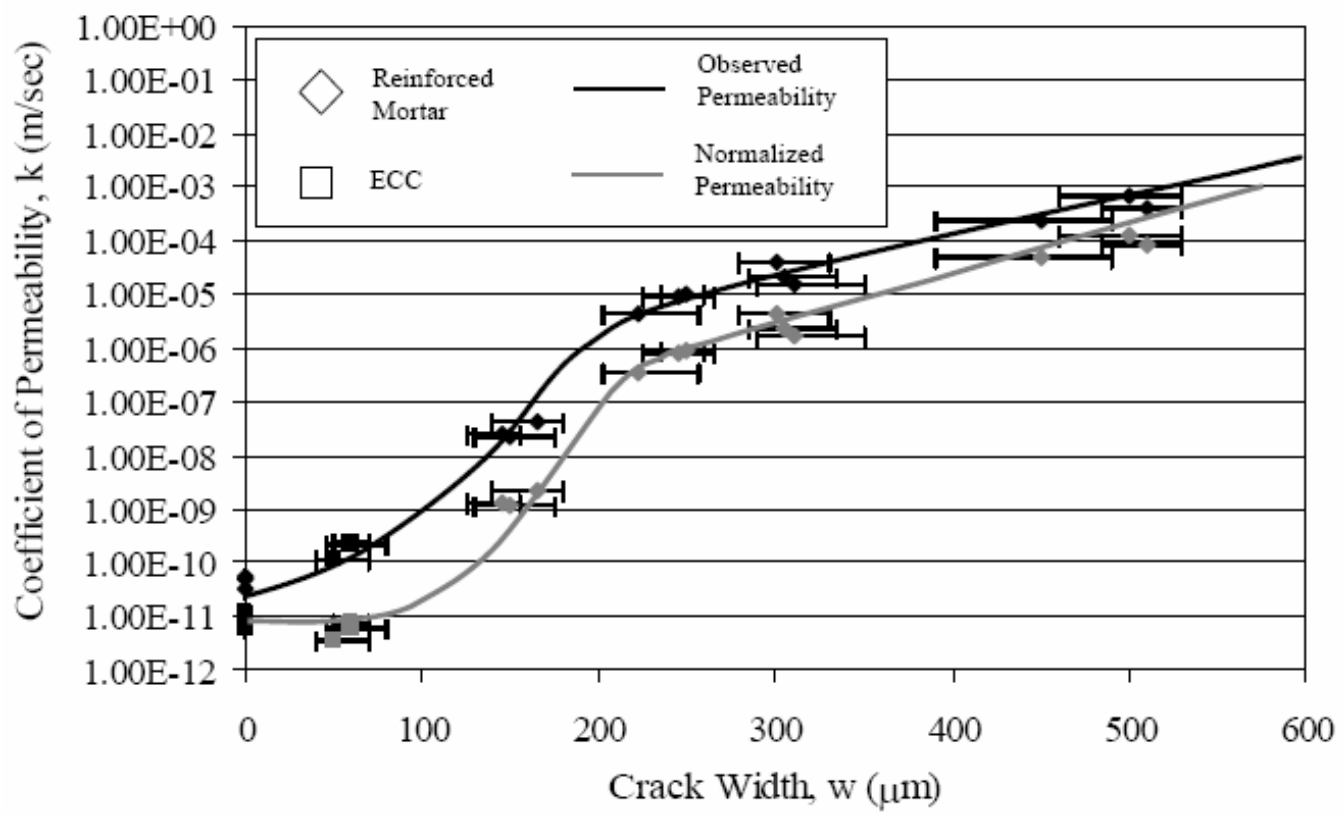

Fig. 6 SHFRCC and steel mesh reinforced mortar water permeability normalised by the number of cracks [27].

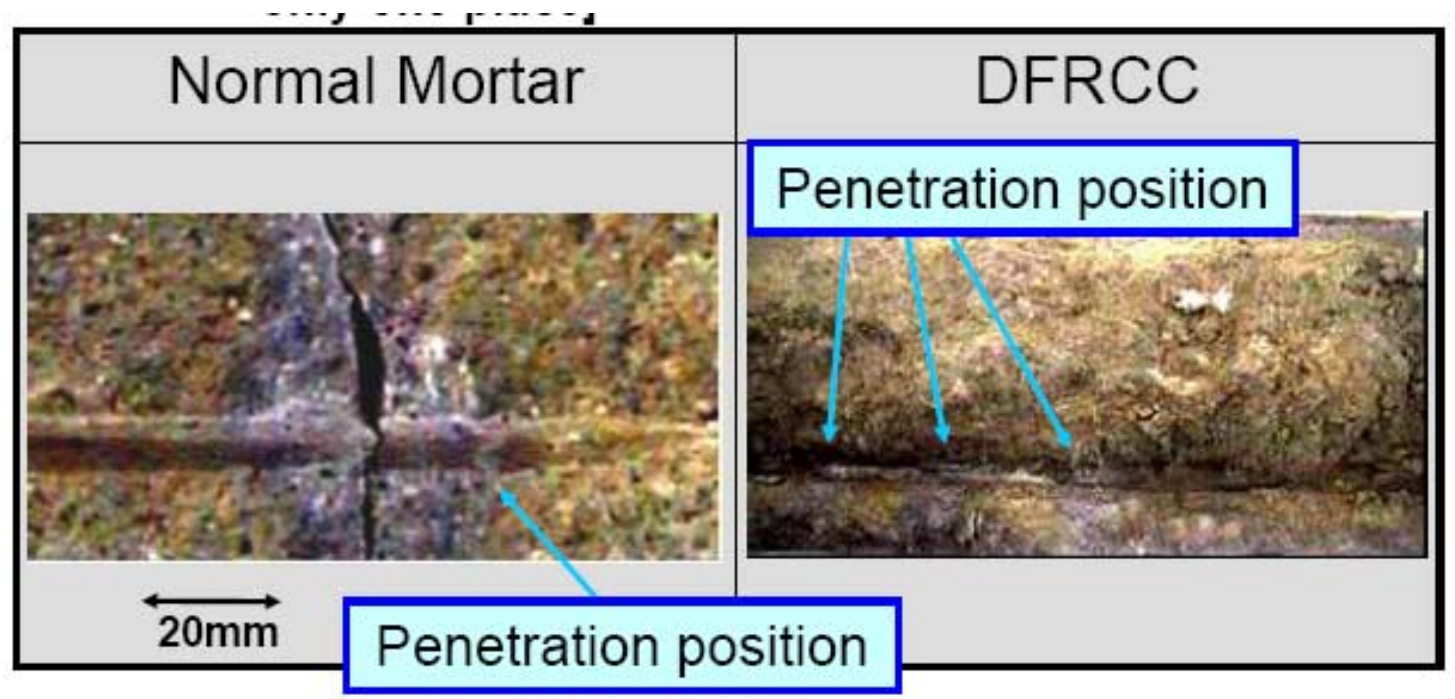

Fig. 7 Penetration of chloride ions in R/Mortar and R/SHFRCC beams [30]. 


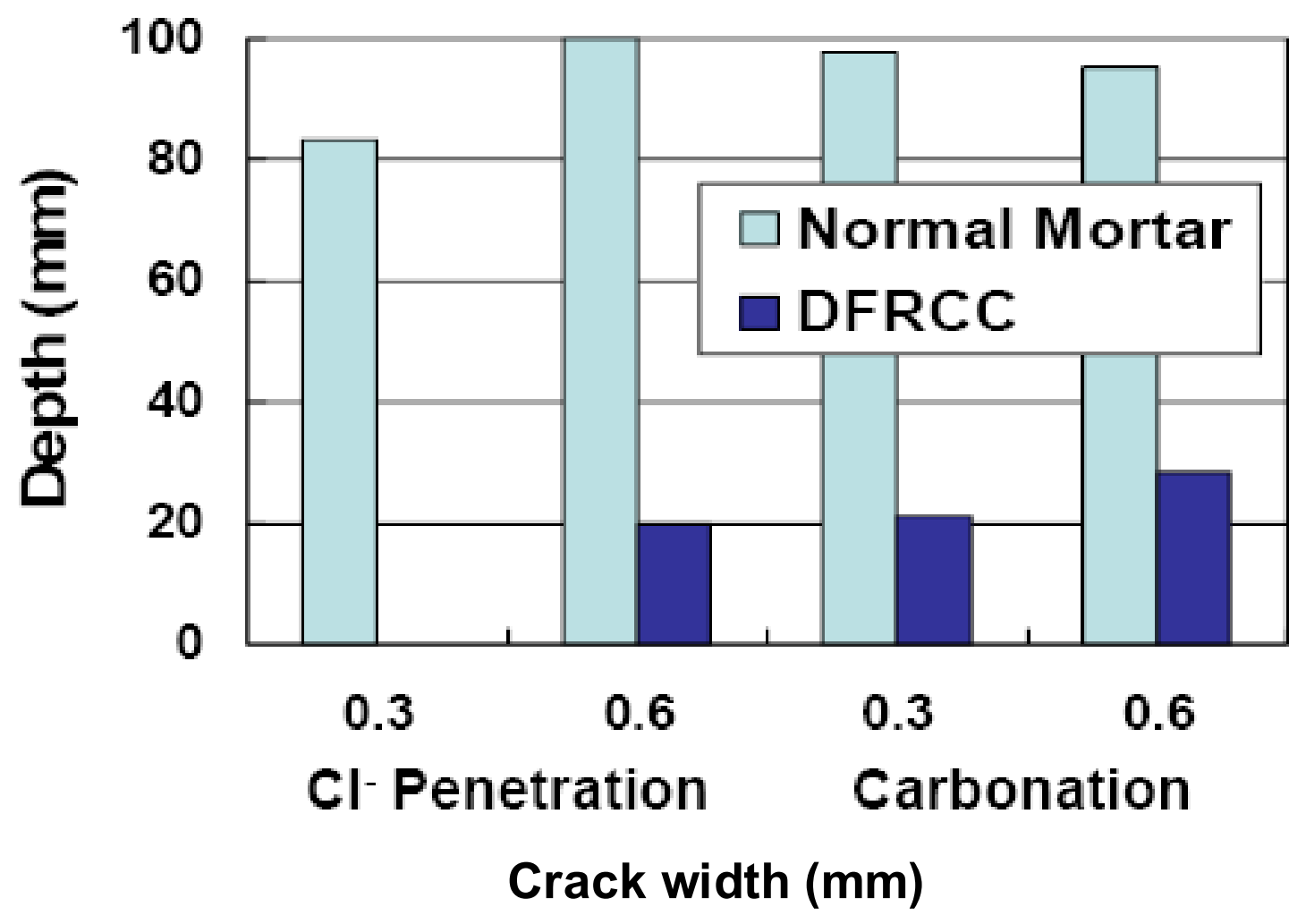

Fig. 8 Measured chloride ion and carbonation penetration depth in R/Mortar and $\mathrm{R} / \mathrm{SHFRCC}$ beams [30]. 


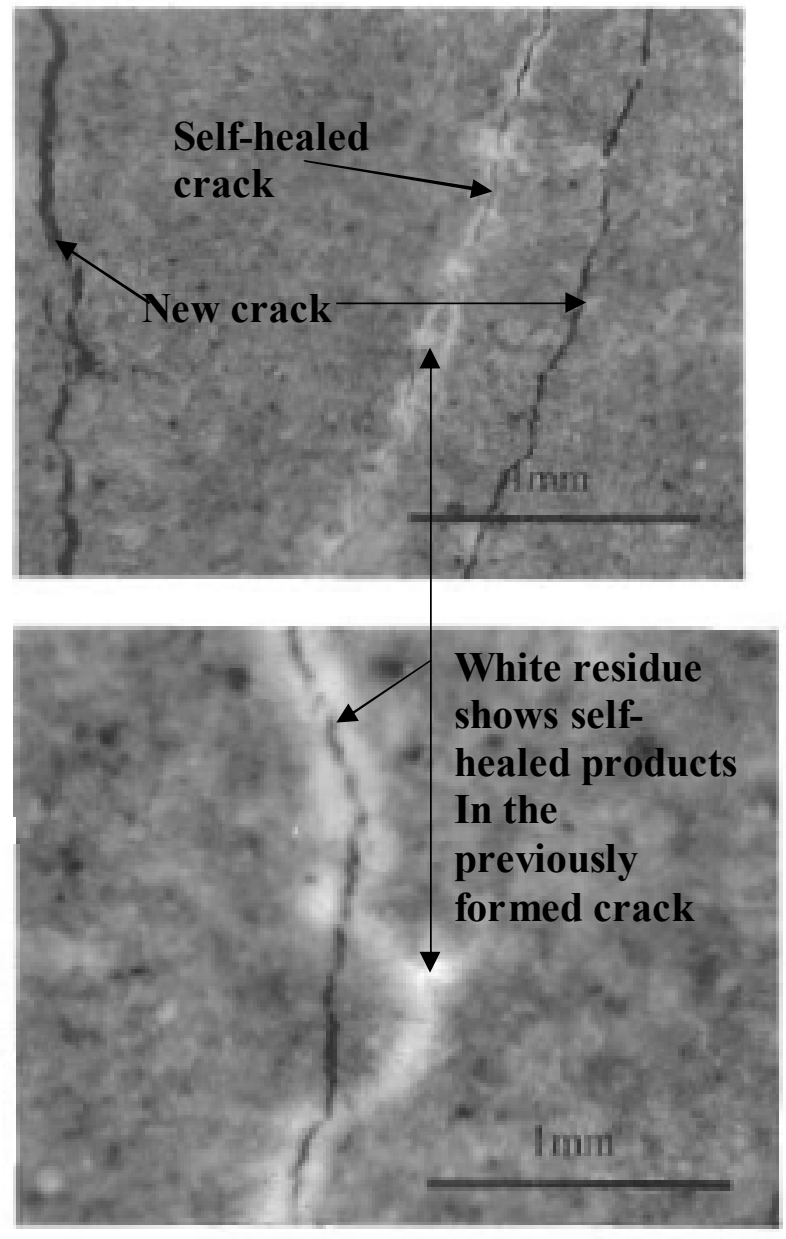

(a) Cracks through virgin SHFRCC material adjacent to a self-healed crack held tight by self-healing product [33]

(b) Formation of new crack path through previously self-healed crack [33];

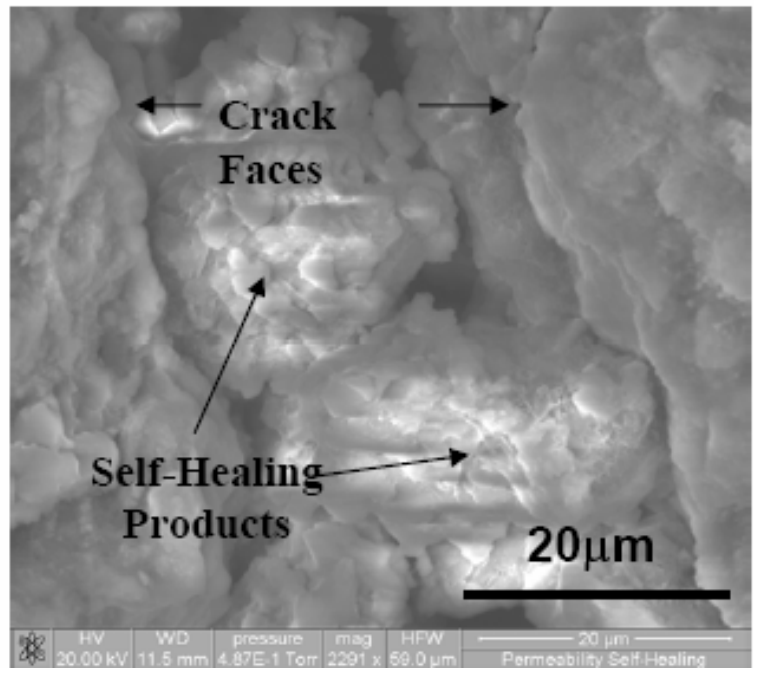

(c) Image indicating self healing products formation in SHFRCC [27].

Fig. 9 Self healing of cracks in SHFRCC 


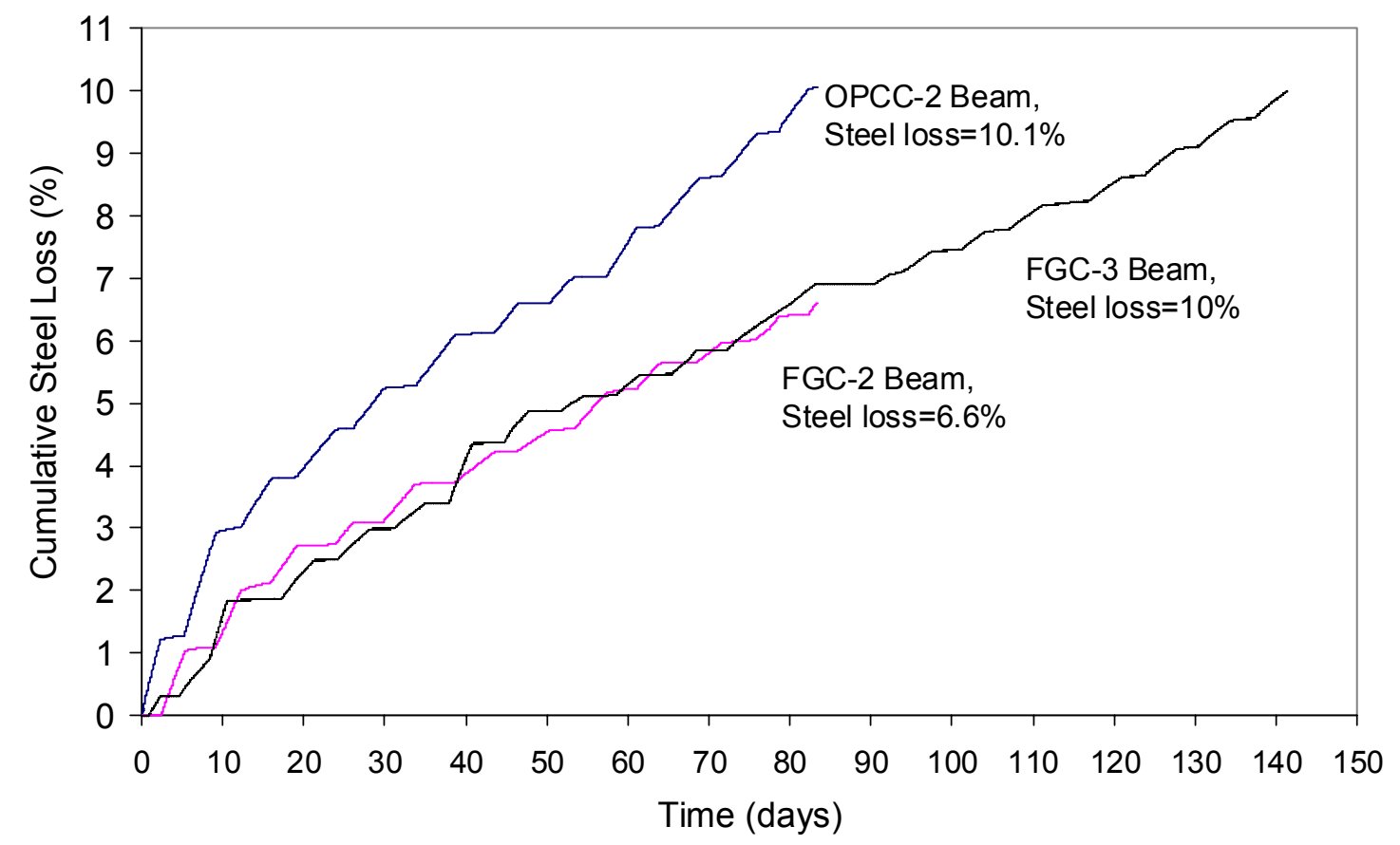

Fig. 10 Calculated cumulative steel loss in RC beam and RC beams with SHFRCC layer [29].

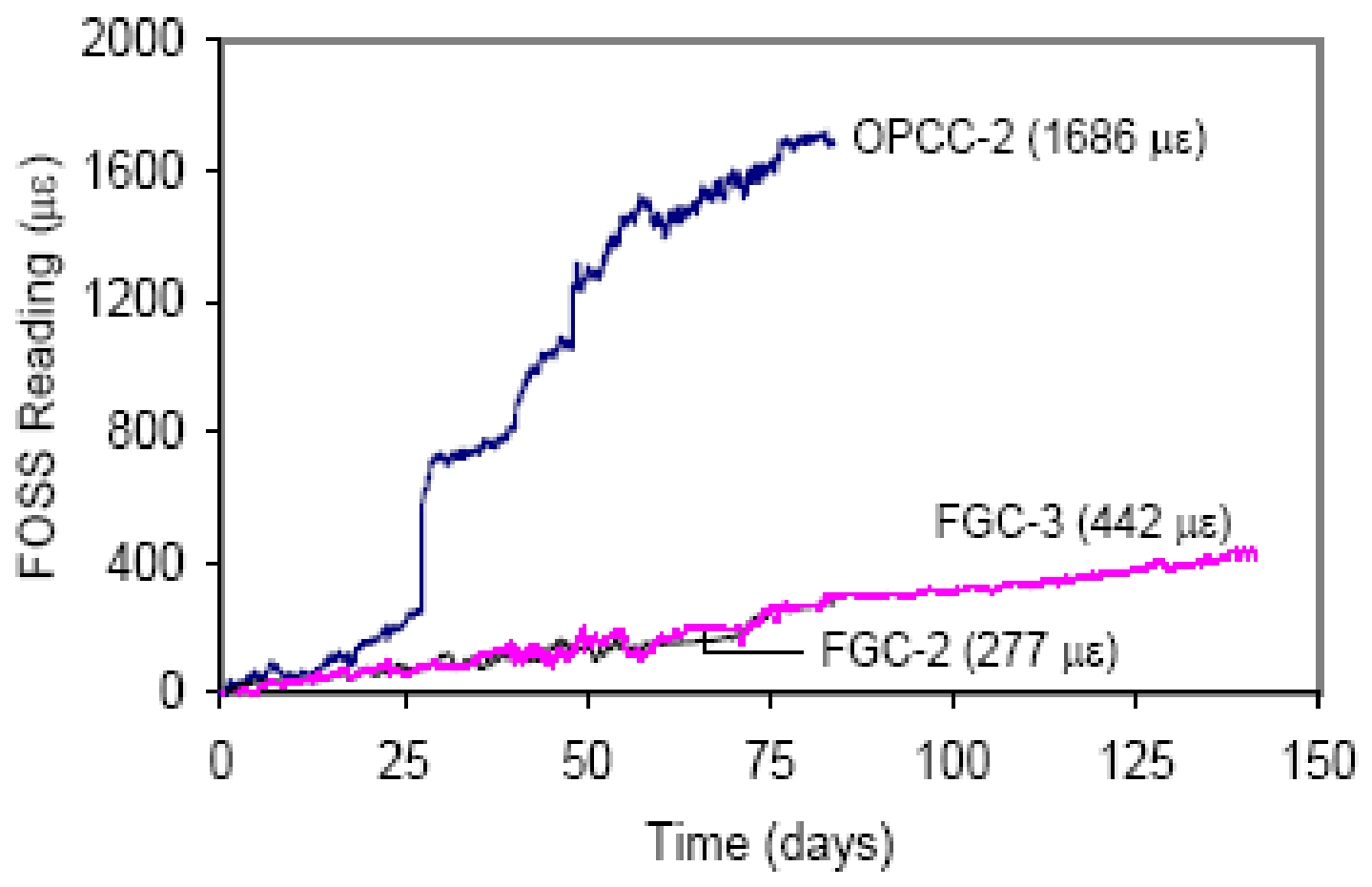

Fig. 11 Corrosion induced tensile strain in concrete as measured by FOSS gauge [29]. 


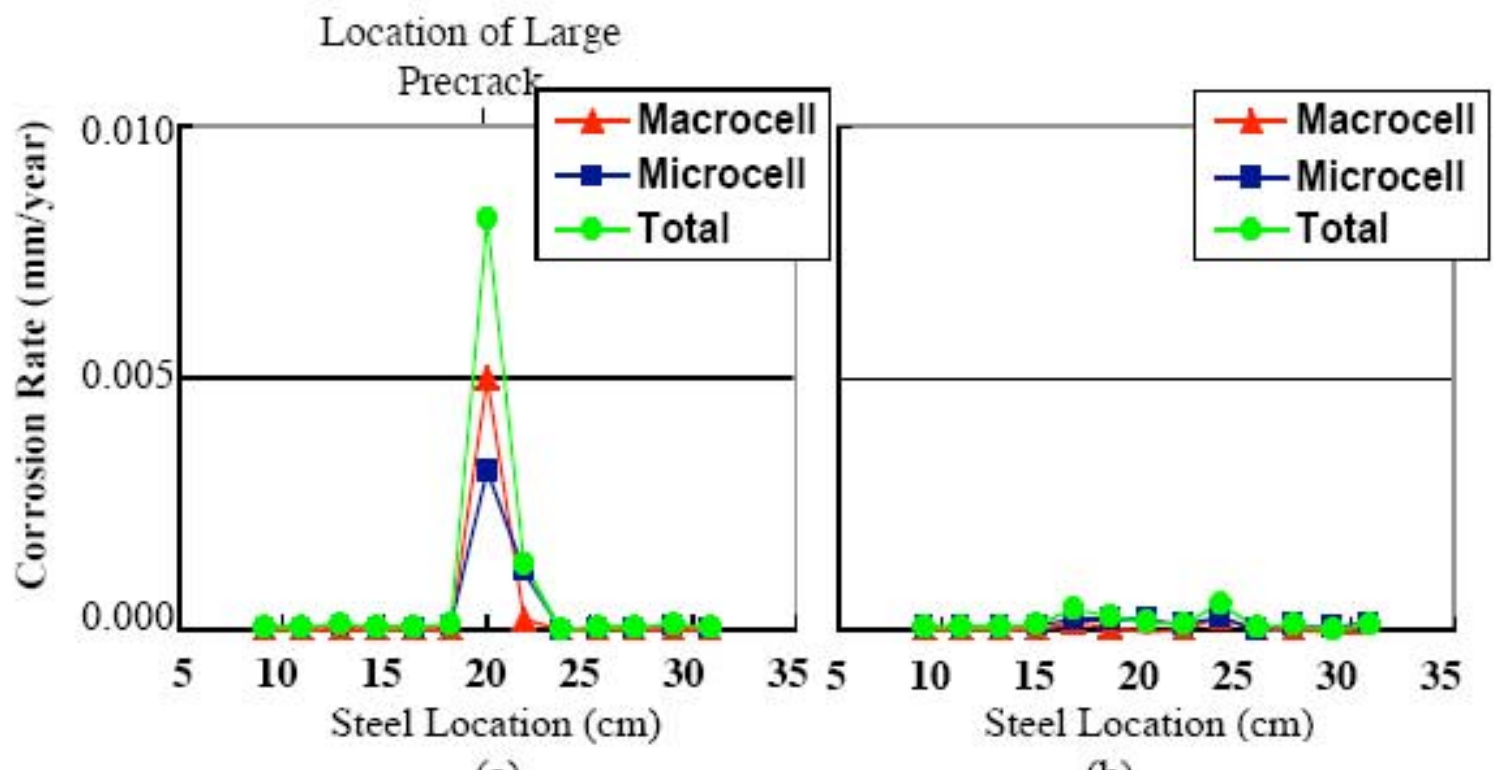

(a)

(b)

Fig. 12 Micro-cell and macro-cell corrosion current in (a) R/C beam and (b) R/SHFRCC beam [30]. 

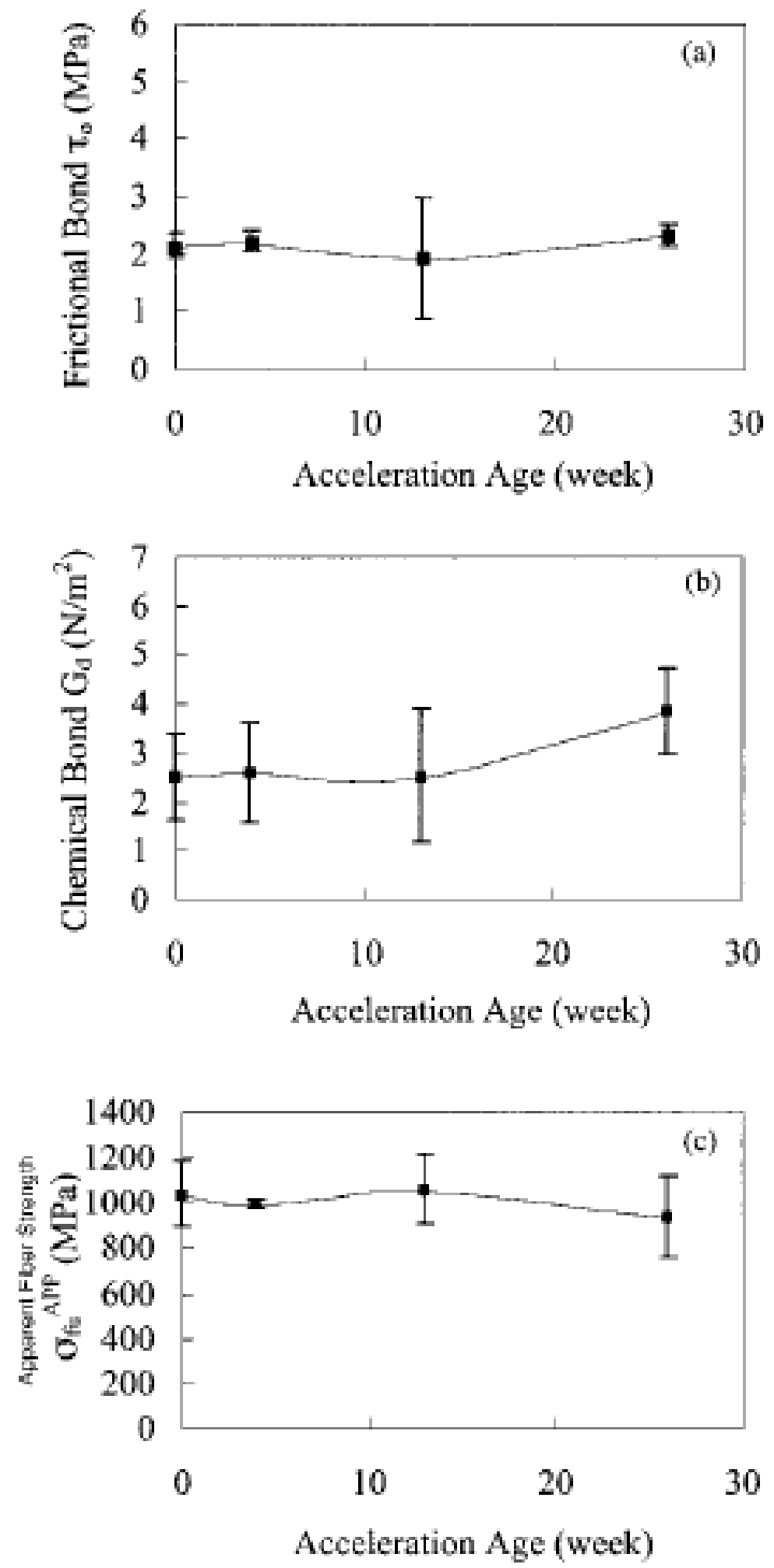

Fig. 13 Effect of hot water immersion on (a) frictional bond; (b) chemical bond; and (c) apparent fibre strength [41]. 


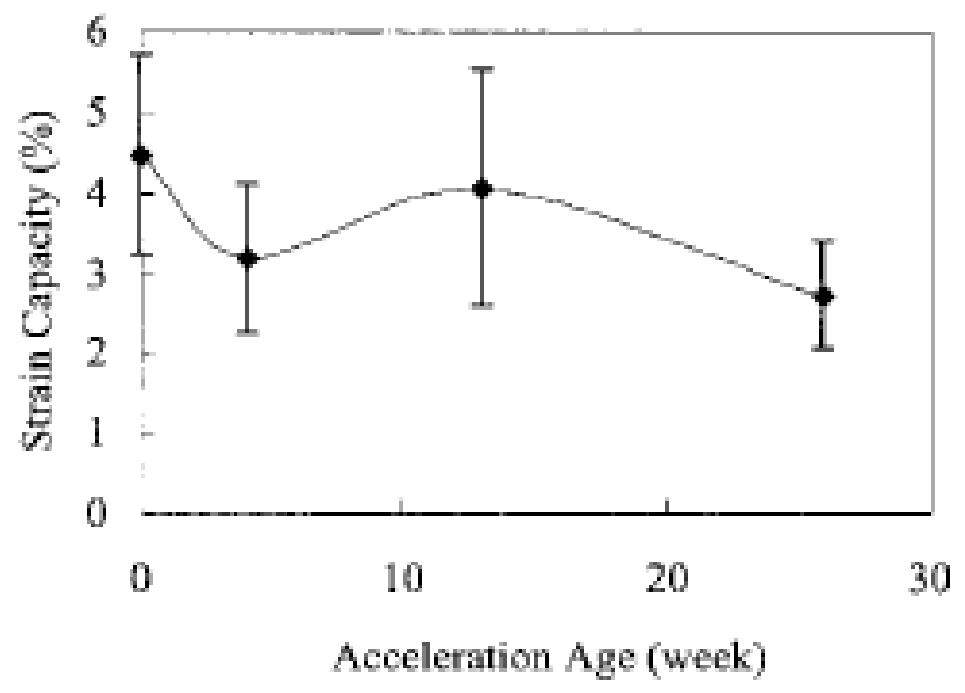

Fig. 14 Influence of hot and humid environmental loading on the tensile strain capacity of PVA fibre reinforced SHFRCC [41].

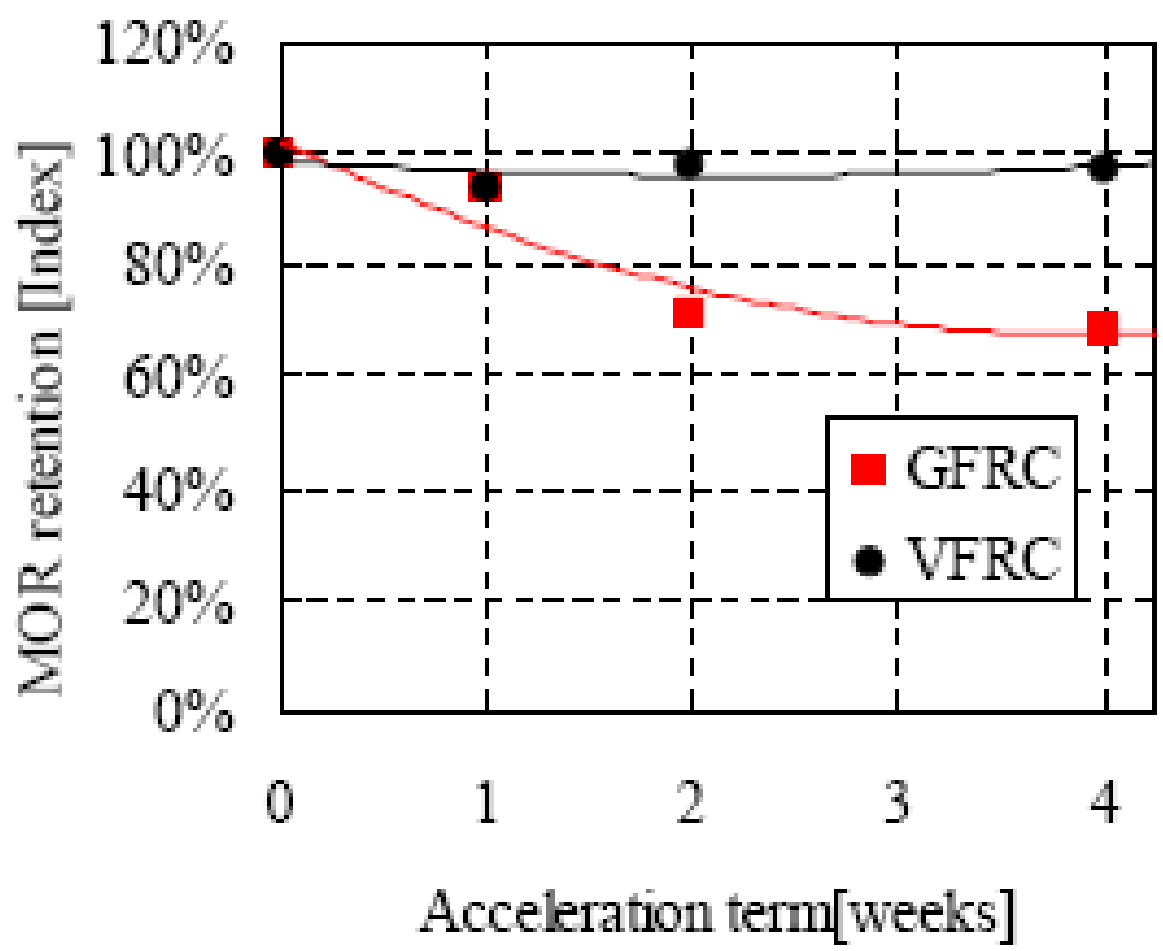

Fig. 15 Reduction of modulus of rupture of SHFRCC reinforced with PVA and glass fibres due to hot and humid environmental loading [42]. 


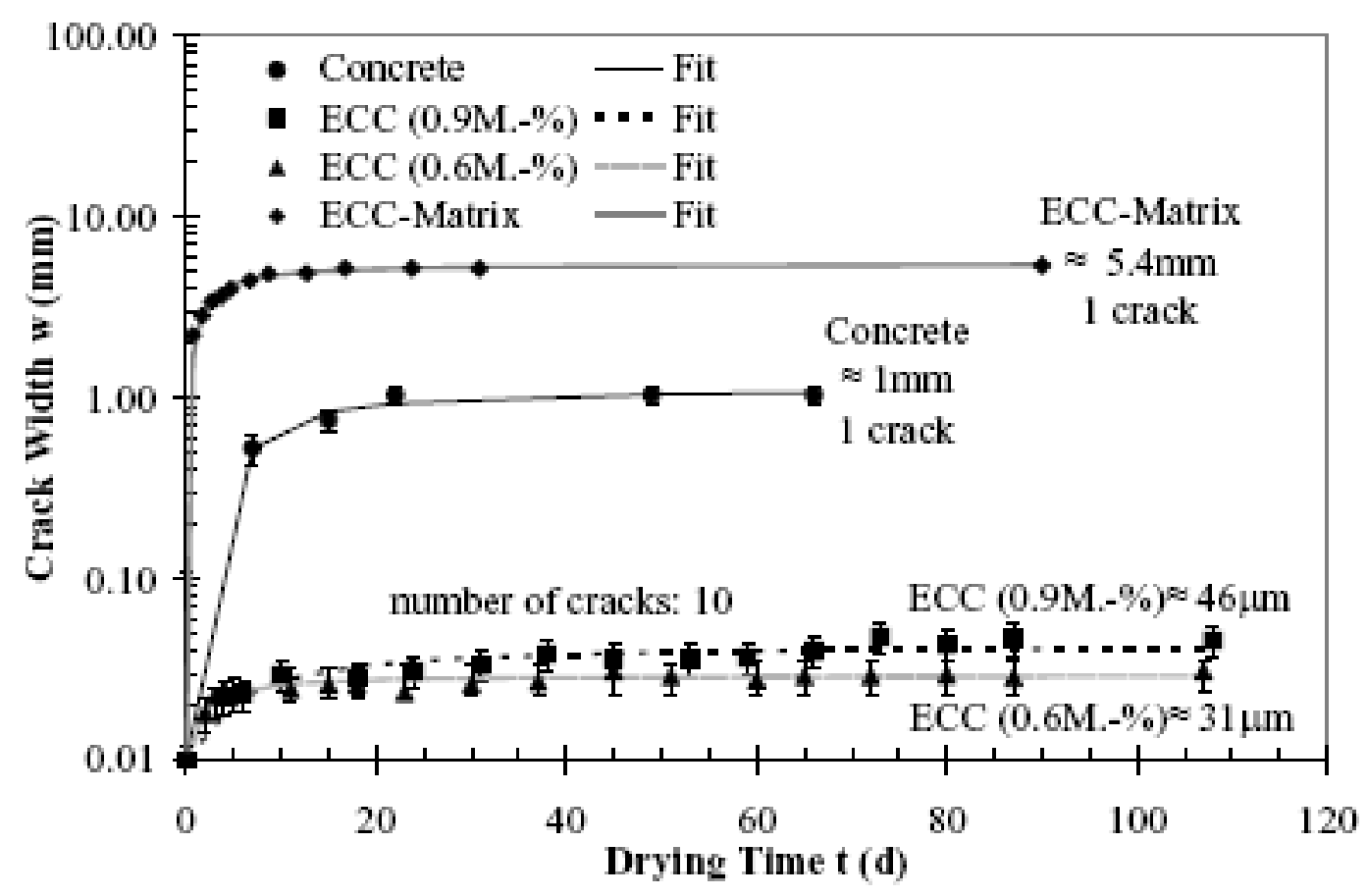

Fig. 16 Crack width and number of cracks in SHFRCC and ordinary mortar/concrete ring specimens due to drying shrinkage [22].

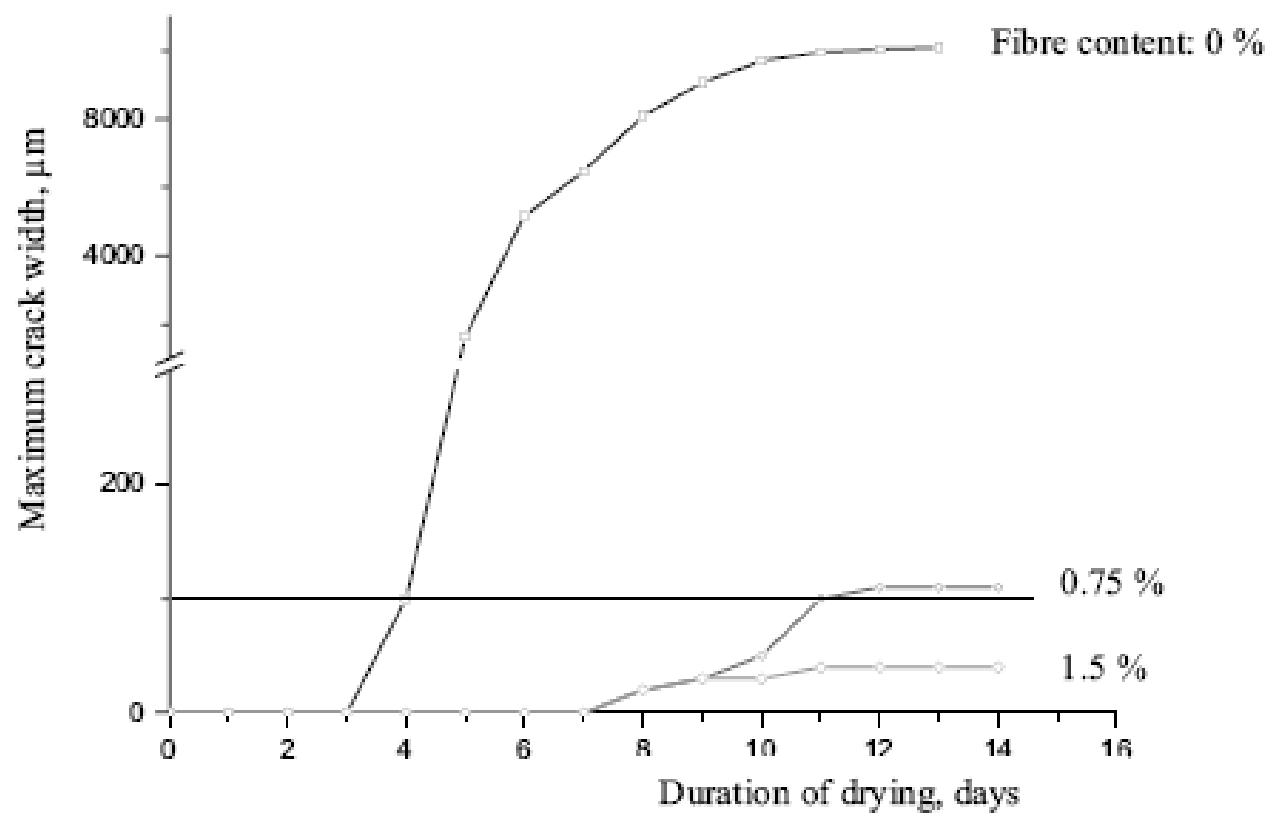

Fig. 17 Crack width in SHFRCC and ordinary mortar ring specimens due to drying shrinkage [43]. 


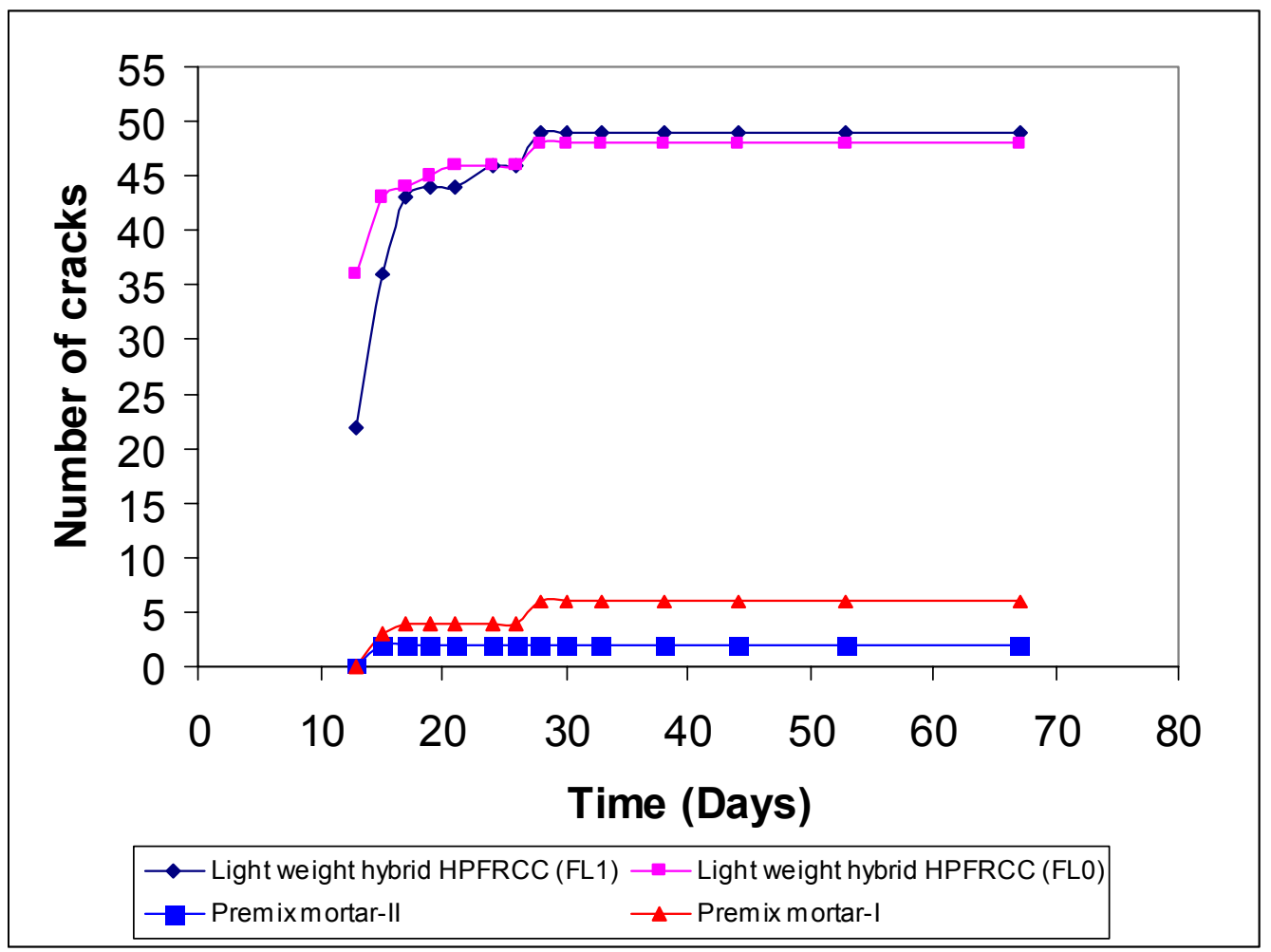

Fig. 18 Development of cracks in the ring specimens with progress of time in the restrained shrinkage test [45].

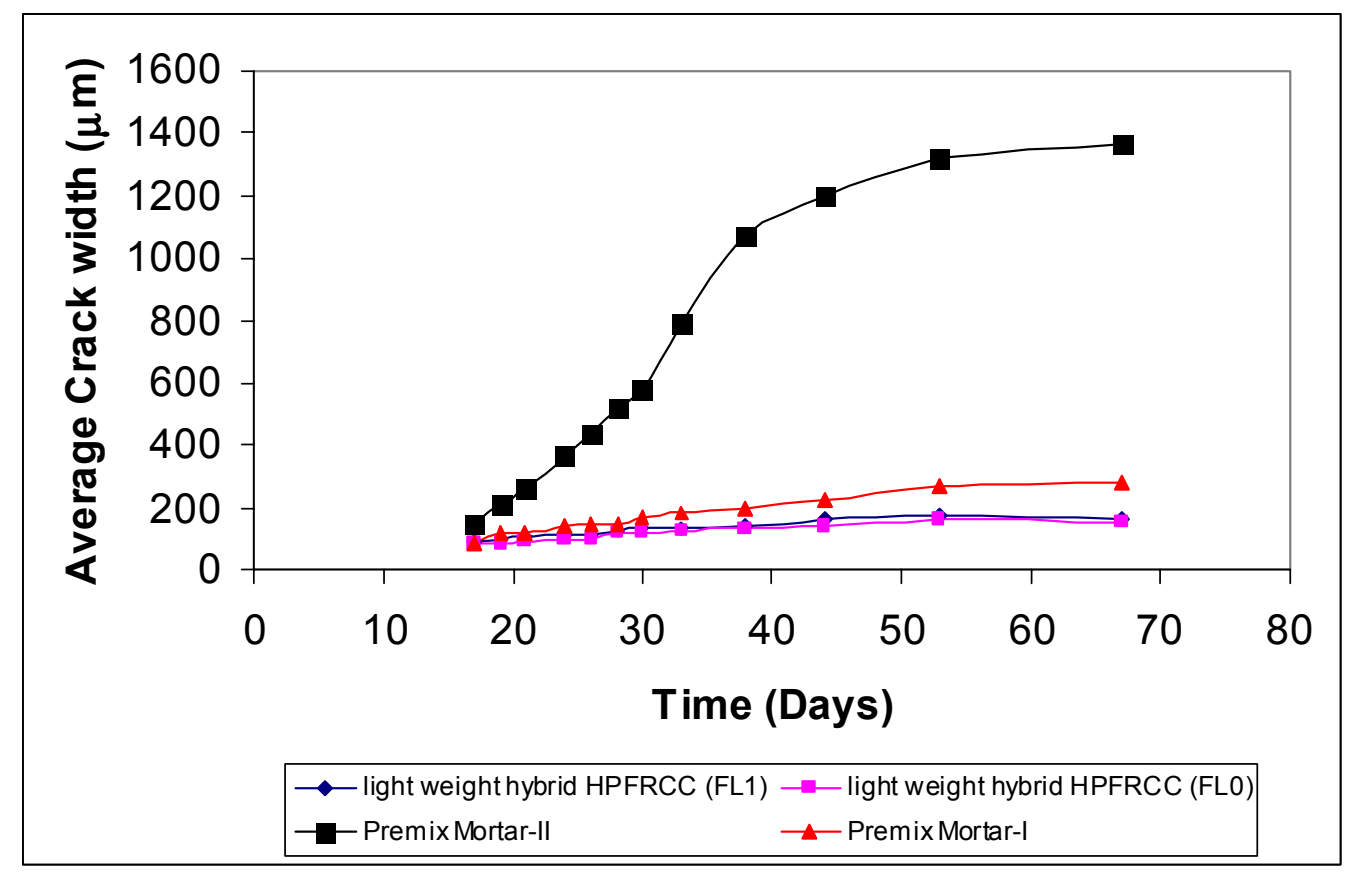

Fig. 19 Development of crack width in the ring specimens with progress of time in the restrained shrinkage test [45]. 


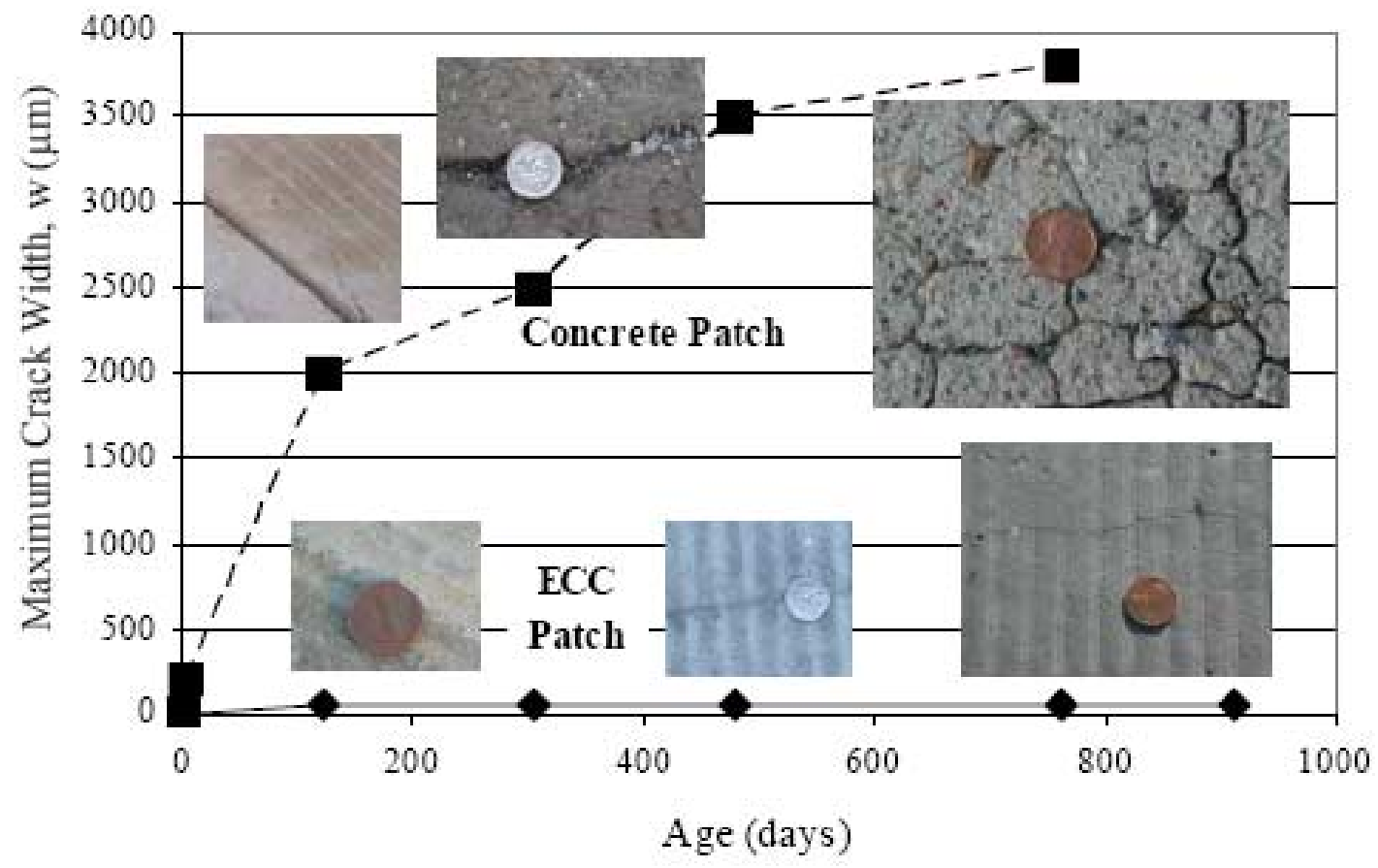

Fig. 20 Development of crack width on ordinary concrete and SHFRCC over time under combined environmental and mechanical loads [40]. 